\title{
Cholesteric Liquid Crystals with a Broad Light Reflection Band
}

\author{
By Michel Mitov*
}

*Centre d'Elaboration de Matériaux et d'Etudes Structurales, CEMES

Centre National de la Recherche Scientifique, CNRS, UPR 8011

29 rue Jeanne-Marvig, BP 94347

F-31055 Toulouse cx 4 (France)

Email: mitov@cemes.fr

Keywords: liquid crystal, cholesteric, Polymer-Stabilized Liquid Crystal, cuticle, light reflection, broadband.

The cholesteric-liquid-crystalline structure, which concerns the organization of chromatin, collagen, chitin, or cellulose, is omnipresent in living matter. In technology, it is found in temperature and pressure sensors, supertwisted nematic liquid crystal displays, optical filters, reflective devices, or cosmetics. A cholesteric liquid crystal reflects light because of its helical structure. The reflection is selective- the bandwidth is limited to a few tens of nanometers and the reflectance is equal to at most $50 \%$ for unpolarized incident light, which is a consequence of the polarization-selectivity rule. These limits must be exceeded for innovative applications like polarizer-free reflective displays, broadband polarizers, optical data storage media, polarization-independent devices, stealth technologies, or smart switchable reflective windows to control solar light and heat. Novel cholesteric-liquid-crystalline architectures with the related fabrication procedures must therefore be developed. This article reviews solutions found in living matter and laboratories to broaden the bandwidth around a central reflection wavelength, do without the polarization-selectivity rule and go beyond the reflectance limit. 


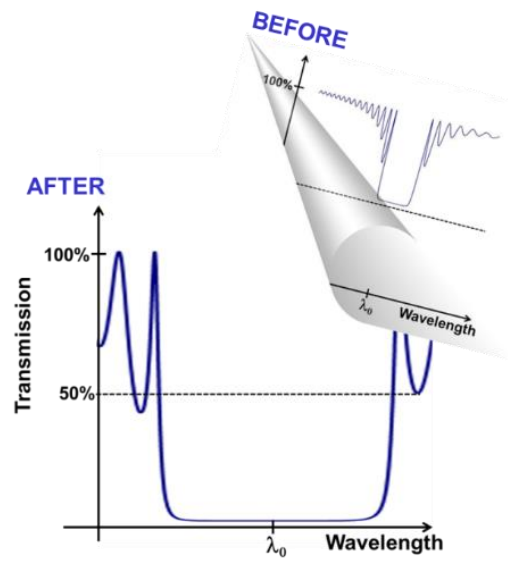

A review on cholesteric-liquid-crystalline helical structures found in living matter and in laboratory and which reflect and polarize light over a broad wavelength band and beyond the classical reflectance limit of $50 \%$ of unpolarized incident light.

\section{Article history:}

Received: July 2012.

Revised: Sep. 4, 2012.

Published online: Oct. 23, 2012

https://doi.org/10.1002/adma.201202913

\section{Introduction}

\subsection{The Cholesteric Liquid Crystal Phase}

The term cholesteric was coined in 1922 by Georges Friedel ${ }^{[1]}$ because this state of matter was discovered in cholesterol esters by Friedrich Reinitzer in $1888^{[2]}$ Since then, cholesteric-liquidcrystalline states have been found in substances not connected with cholesterol. Another name for the cholesteric phase is thus the chiral nematic phase, which stems from the fact that the phase is indeed the chiral version of the nematic phase, as shown below. 


\subsubsection{Structure}

The cholesteric liquid crystal (CLC) phase exhibits a spontaneous helical structure with a twist axis perpendicular to the local director (Figure 1.a), which comes in whole or in part from the molecular chirality of rod-like molecules.

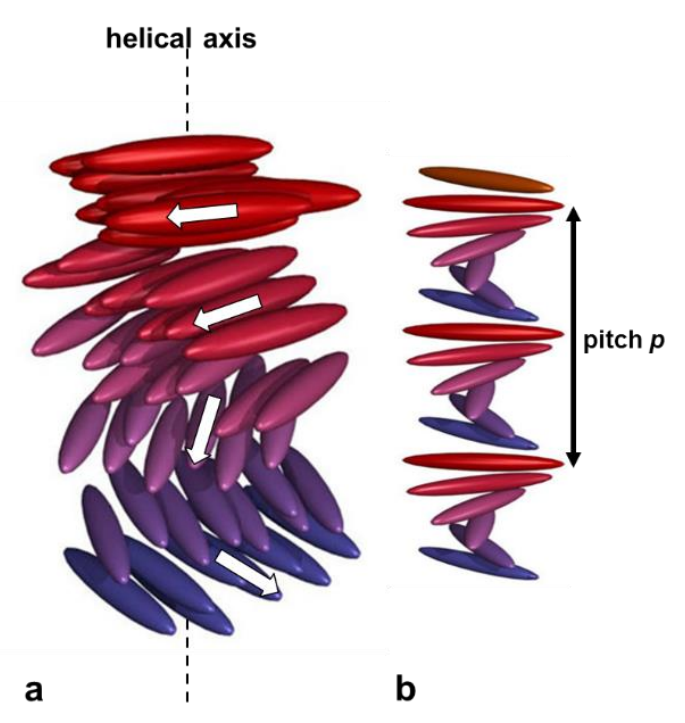

K. G. Yager, Brookhaven National Lab, NY, USA.)
Figure 1. (a) Helical structure of the cholesteric liquid crystal phase. The twist in the arrangement of rod-like molecules is shown with the help of the rotating white arrow. A partial twist is represented. (b) A complete revolution of the arrow along the helical axis occurs over a length equal to the pitch. (Adapted with permission of authors from a figure by C. J. Barrett, McGill Univ., Montreal, Canada, and

If the structure were cut in a direction perpendicular to the helical axis, local nematic order would appear. A nematic liquid crystal (NLC) phase is an achiral phase that exhibits a purely orientational order of elongated molecules. The cholesteric structure is often drawn as a stack of layers with an orientational order of molecules in each plane and a rotation by a constant angle of each plane with respect to its neighbors. However this representation is only a guide for the observer and these layers have no physical reality; the CLC phase is not a layered system, whereas the smectic LC phase is: the molecules are preferentially located in layers, with an orientation normal (oblique) to the layers in the smectic A (C) phase. When the CLC structure is modeled as a layered system ${ }^{[3,4]}$, each layer behaves 
like a uniaxial anisotropic medium with the slow axis parallel to the rod-like molecules and the fast axis perpendicular to them. The two axes twist regularly and without discontinuity from "layer" to "layer". When light propagates through a CLC in the Bragg regime (see section 1.2.1), the medium behaves like a multilayer system, which produces interference colors.

The cholesteric phase is characterized by two structural parameters: the helical pitch $p$ and the twist sense.

(i) The helical pitch $p$ gives the distance along the helical axis that corresponds to a rotation of $360^{\circ}$ in the orientation of the rod-like molecules (Figure 1.b). Owing to the head-tail symmetry of the molecules, the periodicity of the cholesteric phase along the helix axis is given by half the pitch. The magnitude of the pitch can vary considerably from a few tens of nanometers to many micrometers. When a small quantity of chiral dopant is added to a NLC, and if miscibility conditions are satisfied, the achiral NLC phase is easily transformed into a CLC phase. This effect can be revealed by a number of measurements including circular dichroism, optical rotation, and helical twisting power (HTP). Circular dichroism and optical rotation can be measured in the chiral isotropic phase whereas HTP can only be defined in anisotropic phases (i.e., chiral NLC and chiral smectic LC phases). The HTP quantifies the ability of a chiral dopant to induce twist deformation of the molecular director in an achiral LC. This parameter is intrinsic to the given chiral dopant and depends on the host-guest combination $^{[5]}$. For a CLC, it reflects the amount of dopant needed to obtain a given pitch. In some limited range of low concentration, the pitch is inversely proportional to the concentration $C$, the HTP $\beta$, and the enantiomeric excess $(e e)^{[6,7]}$ of the dopant: $p=1 /(\beta . e e . C)$.

(ii) The twist sense determines a left- or right-handed helix and depends on the configuration of the chiral group(s) within the molecule. To date, no means exist to predict which chiral molecular configuration will give a certain helix handedness. There is no simple correlation between the twist sense and the handedness of a chiral dopant. Although empirical rules exist, the question of the 
relationship between the macroscopic phase chirality and the molecular chirality still awaits a conclusive answer. ${ }^{[8]}$ Both the absolute value of the pitch and the sign of the twist sense of a given material may be influenced by several factors that are not necessarily related to chirality. For example, the twist sense may be different for the same chiral dopant in different NLC hosts. ${ }^{[9,10]}$

\subsubsection{Cholesteric structure in living matter}

The study of liquid crystals offers very interesting insights into many physical aspects of biological morphogenesis and provides a considerable source of inspiration for the fabrication of biomimetic systems, as examples of topical research subjects. Their study is essential to develop ideas about the miniaturization of sensors or actuators, implants of biomechanical interest, and controlled-release drugs. ${ }^{[11]}$ A great number of tissues, cell membranes, and organelles show an organization that is related to the molecular structure of nematic (e.g., myofibrils in striated muscle), smectic (e.g., phospholipid bilayers), and cholesteric LC phases. ${ }^{[1-13]}$

Chirality is one of the most important features of living matter. Cholesteric-liquid-crystalline structures are omnipresent in living matter and are involved in the organization of cholesterol esters, ${ }^{[14]}$ in vivo and in vitro chromatin (a combination of DNA and proteins), ${ }^{[15-17]}$ polysaccharides and cellulose derivatives,${ }^{[18,19]}$ collagen in cornea, ${ }^{[20]}$ compact bone ${ }^{[21]}$ or fish scale, ${ }^{[22]}$ or chitin in cuticles (outer shells) of crabs, ${ }^{[23]}$ insects, ${ }^{[24]}$, and many arthropods. ${ }^{[25-27]}$ The first secretory step in the formation of bones and arthropod carapaces involves the hardening of the organic matrix, which exhibits a liquid crystalline organization, due to crosslinks between the biopolymer molecules and subsequent mineralization.

The implications and the complete role of the cholesteric structure in living matter are far from being fully defined. 


\subsubsection{Cholesteric structure in man-made materials}

The twisted structure of the CLC phase concerns many applications in optics. Lyotropic LCs are very widely used in cosmetics and beauty cares. ${ }^{[28]}$ CLC formulations may be used to screen UV light and, in make-up cosmetics, as a coloring agent to obtain opalescent and striking iridescent visual effects that depend on the incidence angle of the light and the angle of observation. Temperature and pressure sensors, ${ }^{[29]}$ supertwisted nematic LC displays (LCDs), ${ }^{[30]}$ tunable bandpass filters and rewritable color recordings, ${ }^{[31]}$ polarizer-free reflective displays, ${ }^{[32]}$ lasing applications, ${ }^{[33]}$ or smart-window prototypes take advantage of the optical properties of the cholesteric phase. Ref. [34] reviews several recent advances in the field.

The cholesteric structure has very far-reaching implications in technology—especially in optics and photonics.

\subsection{Main Optical Properties of Cholesteric Liquid Crystals ${ }^{[35-39]}$}

As discussed below, a properly oriented slab of CLC is a multifunctional material: it is at the same time a reflector, a notch filter, a polarizer, and an optical rotator.

\subsubsection{Selective light reflection and optical activity}

The helical structure of CLCs gives rise to the fundamental property of selective reflection of light. This phenomenon can readily be observed by the naked eye as an iridescent color when the CLC confined between glass plates presents a planar texture - for which the helical axis is perpendicular to the surfaces - and the pitch $p$ is in the range of the wavelength of visible light. At normal incidence 
(i.e., for light propagating along the helical axis), the maximum of selective reflection occurs at the wavelength $\lambda_{0}$ which is directly related to $p$ by $\lambda_{0}=n p$ where $n$ is the average refractive index [ $n=$ $\left(n_{\mathrm{o}}+n_{\mathrm{e}}\right) / 2$, where $n_{\mathrm{o}}$ and $n_{\mathrm{e}}$ are the ordinary and extraordinary indices or refraction, respectively, and which are measured in directions perpendicular and parallel to the local (uniaxial) director, respectively]. Circularly polarized (CP) light having the same sense as the helix twist is totally reflected (more details in the following section), a property that is often referred to as Bragg reflection by analogy with X-ray diffraction, although only the first-order Bragg reflection is possible for normal incidence. All order reflections occur at oblique incidence or when the helical structure is distorted.

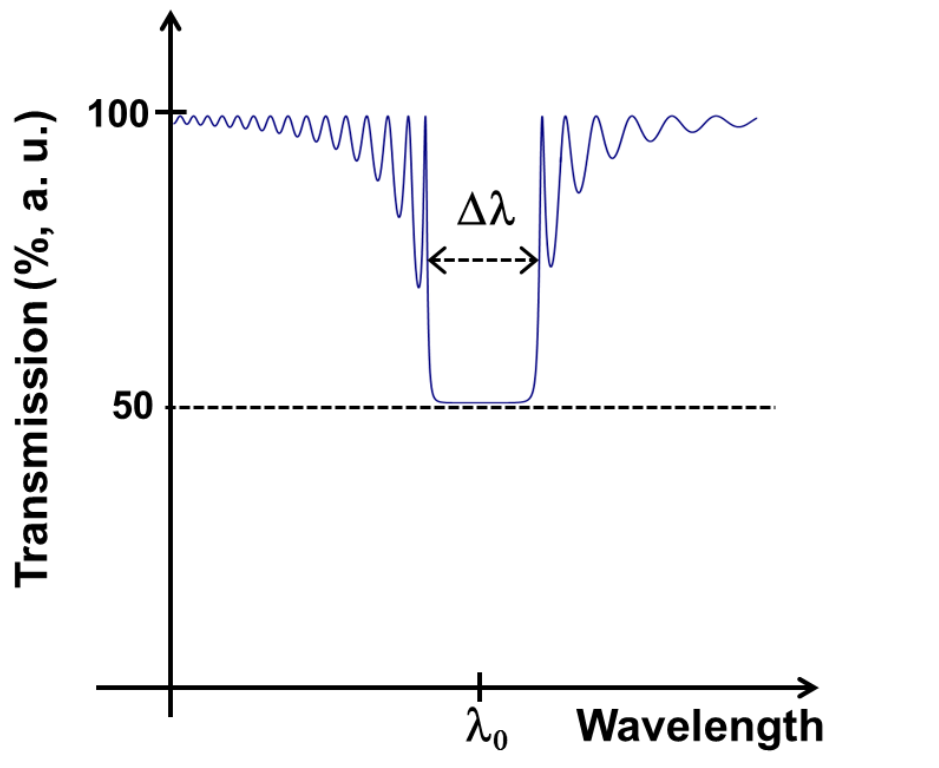

Figure 2. Theoretical transmittance spectrum of a cholesteric liquid crystal at normal incidence and when incident light is unpolarized (courtesy of G. Agez, CEMES-CNRS, Toulouse, France). The negative peak in the measurement is not due to absorption, as in typical polarizers, but to reflection. It could be checked by the coincidence of the positions of peaks in separate measurements of reflection and circular dichroism. The wavelength range may be in the UV, visible, or IR. The position of the band gap is given by the central wavelength $\lambda_{0}$, which is directly related to the pitch of the helical structure. By convention, the spectral bandwidth $\Delta \lambda$ is measured at the half-height of the peak. $\Delta \lambda$ increases with the birefringence of the material. Due to the polarization-selectivity rule, the reflected intensity is limited to $50 \%$. It increases with increasing film thickness and, in correlation, with the number of 
pitch lengths, to finally give a flat-topped peak under the condition that the texture remains perfectly planar (i.e., the helical axis is everywhere perpendicular to the surfaces of the cell). Above a threshold thickness, the cholesteric slab will indeed have a tendency to exhibit a light scattering focal-conic texture. The reflection properties of cholesteric liquid crystals at normal incidence are described by the theory of de Vries. ${ }^{[226]}$ The small subsidiary oscillations (or side lobes) are a direct consequence of a phenomenon of interference between the two surfaces of the sandwich cell confining the cholesteric layer. ${ }^{[227,228]}$ The sinusoidal modulation of the profile of oscillations strongly depends on the film thickness.

The reflectance properties are very often deduced from transmittance spectra (Figure 2) when investigations are made with clear-cut planarly oriented cholesteric samples that do not absorb or scatter light. The reflection color depends on: (i) parameters proper to the material such as the molecular chirality or the concentration of chiral dopant, the pitch, and the optical indices; (ii) external parameters such as temperature, mechanical pressure, electric or magnetic field, angle of incidence of the light ( $\lambda_{0}=n p \cos \theta$ where $\theta$ is the angle between the helical axis and the direction of propagation), the polarization of the incident light, radiation (in the case of photoinduced effects due to the presence of photoswitchable molecules), or the geometry of the experimental cell (e.g., treatment of surfaces, gap value).

At normal incidence, the bandwidth $\Delta \lambda$ is related to the birefringence $\Delta n\left(\Delta n=n_{\mathrm{e}}-n_{\mathrm{o}}\right)$ and $p$ by: $\Delta \lambda=p \Delta n$. Incident light with a wavelength $\lambda$ out of $\Delta \lambda$ is simply transmitted. $\Delta \lambda$ is currently measured like the width of the band gap at half height. $\Delta \lambda$ is limited to a few tens of nanometers in the visible spectrum because the birefringence is typically limited to 0.5 . This limit is not a problem when the selectivity of the light reflection is desired for many applications such as narrow-band polarizers and filters, thermography, and, more generally, for sensors. However, the bandwidth must be 
dramatically increased for innovative applications like full-color or white-on-black reflective polarizer-free displays, broadband polarizers, organic optical data storage media, or smart switchable reflective windows to control solar light and heat. When a conventional (absorptive) polarizer is exposed to unpolarized light, one of the two orthogonal linearly polarized components of the light is transmitted whereas the other component is absorbed by the polarizer. At best, only $50 \%$ of the incident light emerges as polarized light, which is a relatively low efficiency. Another drawback is related to the absorption of the nontransmitted component, which may give rise to heating of the polarizer and uncontrolled changes in the properties of the polarizer. At high incident light intensity, it can even lead to the destruction of the polarizer. With cholesteric broadband polarizers, it is possible to convert unpolarized light into polarized light very efficiently and over a broad range of wavelengths. Considering all fields of research, circularly polarized light restricted to a narrow frequency range is a major limitation in many applications. ${ }^{[40]}$

Increasing the birefringence $\Delta n$, and consequently increasing $\Delta \lambda$, may be done by synthesizing tailor-made compounds; namely, highly polarizable groups with high electron density (benzene rings, polyaromatic systems, or acetylene linking groups), ${ }^{[4]}$ nematogens laterally attached to a polymer backbone via a flexible spacer, ${ }^{[42-44]}$ or chiral side-on tolane acrylates. ${ }^{[45]}$ However, CLC materials with very high birefringence are difficult to synthesize; they may have poor stability and absorption bands in the wavelength region of interest. In any case, the maximum $\Delta n$ that can be obtained is 0.5 . In fact, most of time, $\Delta n$ is less than 0.3 , so that the associated $\Delta \lambda$ is less than $100 \mathrm{~nm}$ (typically ranging between 30 and $50 \mathrm{~nm}$ ). Novel helical liquid crystalline architectures are therefore desirable. For these fundamental reasons, the fabrication of advanced cholesteric materials with a broad band gap is thus challenging.

The helical structure of CLCs gives rise to an exceptionally large optical activity, which occurs on each side of the reflection band. An optical rotation up to $10^{3}$ to $10^{5} \% / \mathrm{mm}$ may occur in the visible 
spectrum, compared with typically values between 0.01 and $100 \% \mathrm{~mm}$ for a chiral liquid (e.g., sugar water) or a crystal (e.g., quartz). The wavelength regions for optical activity are separated by the Bragg band and have opposite signs of rotation. The optical rotation of a CLC depends strongly on the wavelength $\lambda$ of the incident light. When the light is transmitted along the helical axis and in the socalled Mauguin regime $(\lambda<<p),{ }^{[46,47]}$ the direction of the polarization of the incident light rotates in the same sense as the twist direction. This mode is used in twisted nematic LCDs.

\subsubsection{Polarization-selectivity rule}

Consider incident light that is linearly polarized, which can be thought of as consisting of a left- and right-handed $\mathrm{CP}$ component. At $\lambda_{0}$ and normal incidence, one of these components is fully reflected by the CLC structure and the electric field pattern in the reflected wave is a helix identical in shape to the cholesteric helix, which contrasts strongly with reflection from a common mirror that undergoes a $180^{\circ}$ phase shift upon reflection and changes handedness. The other component is simply transmitted. Right-hand circularly polarized (RHCP) and left-hand circularly polarized (LHCP) light are defined, following the usual convention, ${ }^{[48]}$ as the electric field vector rotating clockwise and counterclockwise, respectively, when viewing into the light source; that is, opposite to the direction of light propagation. The fact that the reflected light is circularly polarized with the same handedness as that of the CLC structure constitutes the polarization-selectivity rule, which is valid only at normal incidence. At oblique incidence the reflected or transmitted light is elliptically polarized.

Thus, a CLC cannot reflect more than $50 \%$ of normally incident unpolarized light and reflects $0 \%$ when the incident beam is circularly polarized with a handedness opposite that of the CLC. However it might be desirable to increase the reflectivity for hyper-reflective (polarizer-free) displays, stealth technologies (also termed low-observable technologies), electro-optical glazing structures (to 
dynamically control electromagnetic radiation), and, more generally, polarization-independent photonic devices (since very high contrast occurs when the right- and left-handed structures reflect the same wavelength). The development for technological applications of novel cholesteric-liquidcrystalline structures that do not obey the polarization-selectivity rule is therefore challenging.

\subsection{Scope of Article}

This article is the first review devoted to the broadening of the reflection band in CLCs. We discuss herein the solutions found in living matter and in laboratories:

- to broaden the bandwidth around a central reflection wavelength (section 2);

- to go beyond the polarization-selectivity rule (section 3); namely, to increase the reflectance above the usual limit of $50 \%$ for unpolarized incident light and, more generally, to associate $\mathrm{CP}$ reflection bands with both helicities.

This review focuses on:

- experimental procedures;

- the relationship between optical properties and a given structure;

- optical properties at equilibrium: the fabrication procedure of the material results in the broadening of the band gap, which is thereafter maintained;

- the broadening of the band gap as a result of light propagation in the $z$ direction; that is, transverse to the CLC layer. This condition allows for uniform optical quality and offers great potential for high-contrast CLCs;

- normal incidence. 
Topics that are out of the scope of the review include:

- multiple band gaps ${ }^{[49-65]}$ for which the reflection consists of the sum of well-defined (separate) narrow peaks;

- cells with different colors in the $x-y$ plane of the layer; ${ }^{[66-73]}$

- broadening of the band gap such as occurs for light scattering, but not reflection, from a polydomain focal-conic texture; $;^{[74]}$

- nonequilibrium conditions such as field-induced ${ }^{[75-80]}$, light-driven ${ }^{[81-84]}$, stress-induced ${ }^{[85]}$ or thermally controlled ${ }^{[60,86,87]}$ broadening of the band gap. The basic property disappears at the same time as the stimulus, or is not displayed if the temperature program is not followed;

- increased reflection and coexistence of double-handed CP reflection bands as an expected consequence of oblique incidence. ${ }^{[88-99]}$ The basic property disappears at normal incidence.

\section{Broadening the Wavelength Band Gap}

\subsection{Multilayer system: from cuticle of Plusiotis boucardi to synthetic materials}

The cuticle of crustaceans and insects is a composite material made of an organic matrix, mainly proteins and chitin (a linear polymer of acetylglucosamine), and a mineral (mainly calcite). The organic matrix is studied after decalcification: the biological fibrils exhibit a twisted organization, which is nothing else than the biological version of the CLC structure. The cholesteric organization is found in the organic matrix of many beetles and is responsible for their iridescent colors, which have fascinated people since the ancient Egyptians, who regarded scarab beetles as sacred objects. As long ago as $1911,{ }^{[100]}$ Michelson studied their unusual optical properties, such as their ability to reflect mainly LHCP light and not RHCP light. 
The cuticle of the beetle Plusiotis boucardi exhibits reflections in the green and red ${ }^{[101]}$ (Figure 3). Investigation of cross-sections of the elytra by transmission electron microscopy (TEM) has revealed the existence of several (curved) layers in the organization of chitin molecules. The green and red reflections come from two CLC structures with distinct pitches (310 and $370 \mathrm{~nm})$. The shorter pitch is at the top of the stack; an orange reflection occurs at $588 \mathrm{~nm}$ but arises from an interference effect between the layers. The biological function of two reflection colors is currently under debate. It would be interesting to explore the possible link between the characteristics of reflection spectra and the sensitivity of the beetle's photoreceptors. Many arthropods are known to be sensitive to polarized light.

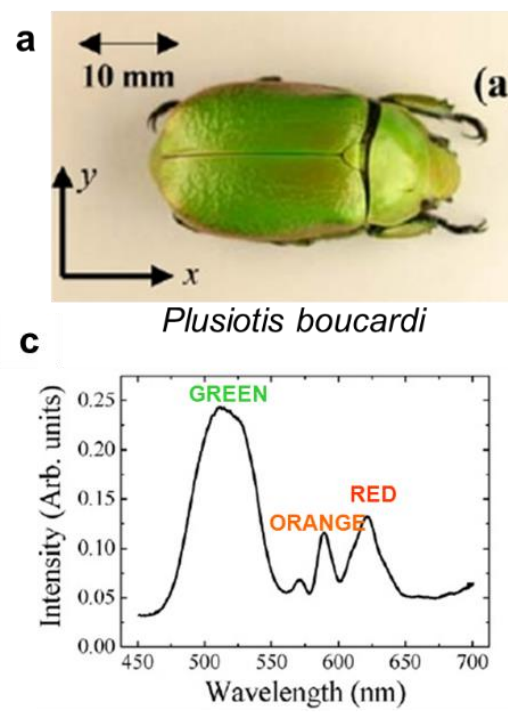

EXPERIMENTAL
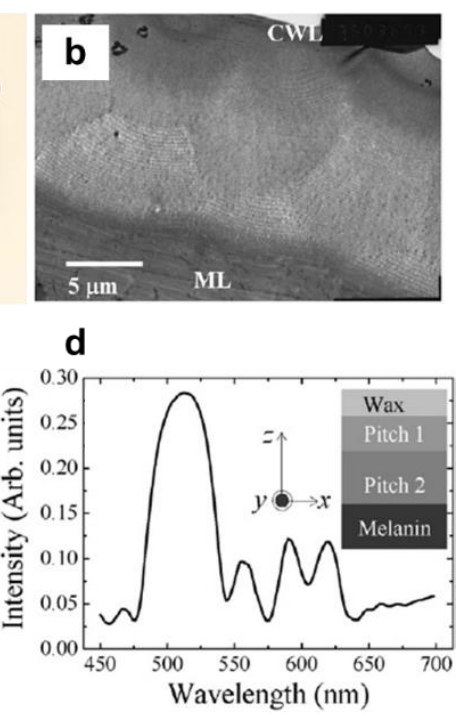

SIMULATED
Figure 3. (a) Plusiotis boucardi

beetle. (b) TEM image of a cross section of the elytron showing the curved and concentric cholesteric layers with two different pitches (CWL: cuticular wax layer. ML: melanin layer). (c) Reflection spectrum from a sample of the

elytron. (d) Simulated spectrum. Inset: scheme of the multilayer system in a cross section. Adapted with permission from Ref. [101]. Copyright 2007, IOP Publishing Ltd. and Deutsche Physikalische Gesellschaft. 
The synthetic replication of cholesteric layers with different pitches is discussed in Refs. [102110]. Several authors show that colors of superimposed CLC coatings sum to produce a gamut greater than that obtained with inks, dyes, and pigments. Several applications for such coatings exist in the field of optical data storage, for which are used stacks of solid layers of CLC polymers (Figure 4) or glass sandwich cells in which a low-molar-mass CLC is infiltered.

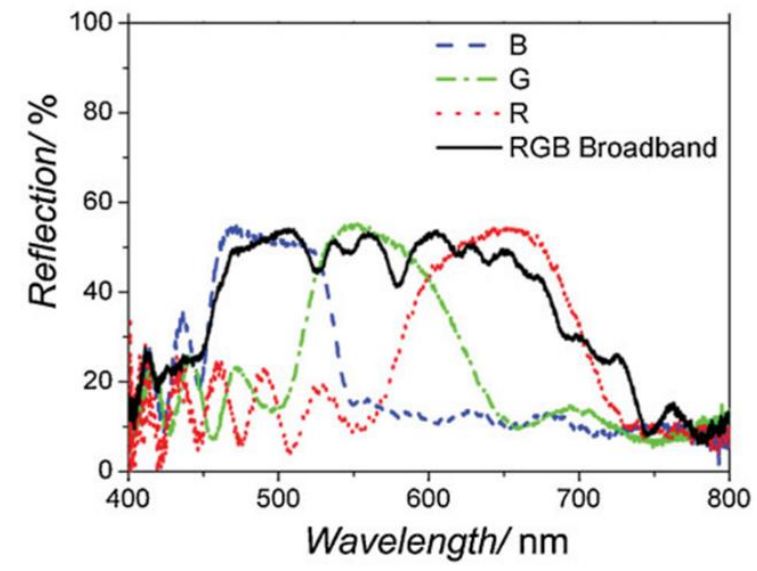

Figure 4. A broadband reflection spectrum (black solid curve) consisting of each reflection spectrum of blue, green, and red cholesteric polymer films. Reproduced with permission from Ref. [110]. Copyright 2010, Wiley-VCH Verlag GmbH \& Co. KGaA, Weinheim.

Although the idea of stacking cholesteric layers with different pitches to increase $\Delta \lambda$ seems to be a simple solution, the implementation of a multilayer material in a device is a complex task as compared with the case of inserting a single layer in a single sandwich-cell. This is all-the-more true when the field switchability is the goal. In addition, physicists working in the field of optics do not like to stack many layers or cells because limits and undesired effects may rapidly appear, such as multiple internal reflections, optical defects, or losses at interfaces. For these reasons, several research groups have put their efforts into fabricating a single cholesteric layer with a graded structure and periodicity—like a pitch gradient. 


\subsection{Pitch gradient: from cuticle of Carcinus manas to polymer-based composite materials}

\subsubsection{The school of nature}

The twisted structure of chitin and protein fibrils in the cuticle of arthropods is recognizable by a characteristic pattern that consists of a set of parallel series of nested arcs, which are observed in thin sections prepared for TEM, as shown by Bouligand. ${ }^{[23]}$ The cholesteric structure of the cuticle of the crab Carcinus manas exhibits a pitch gradient ${ }^{[12,111]}$ (Figure 5). The distribution of the pitch varies greatly, even in the most regular regions, from 0.25 to $10 \mu \mathrm{m}$, and reflection mainly occurs in the IR. The question of a hypothetical biological function of such an arrangement remains unsolved. We may speculate that Carcinus monas is equipped with a reflector to avoid overheating, which can be useful when the crab spends a lot of time on the beach; in that sense, a broadened bandwidth is understandable. Although experiments on IR reflections from the cuticle of arthropods were done in the past,${ }^{[112-114]}$ modern characterizations and research in this area are still missing. TEM investigations of pitch gradient structures in several insect cuticles have also been reported. ${ }^{[24,115]}$ 
Review
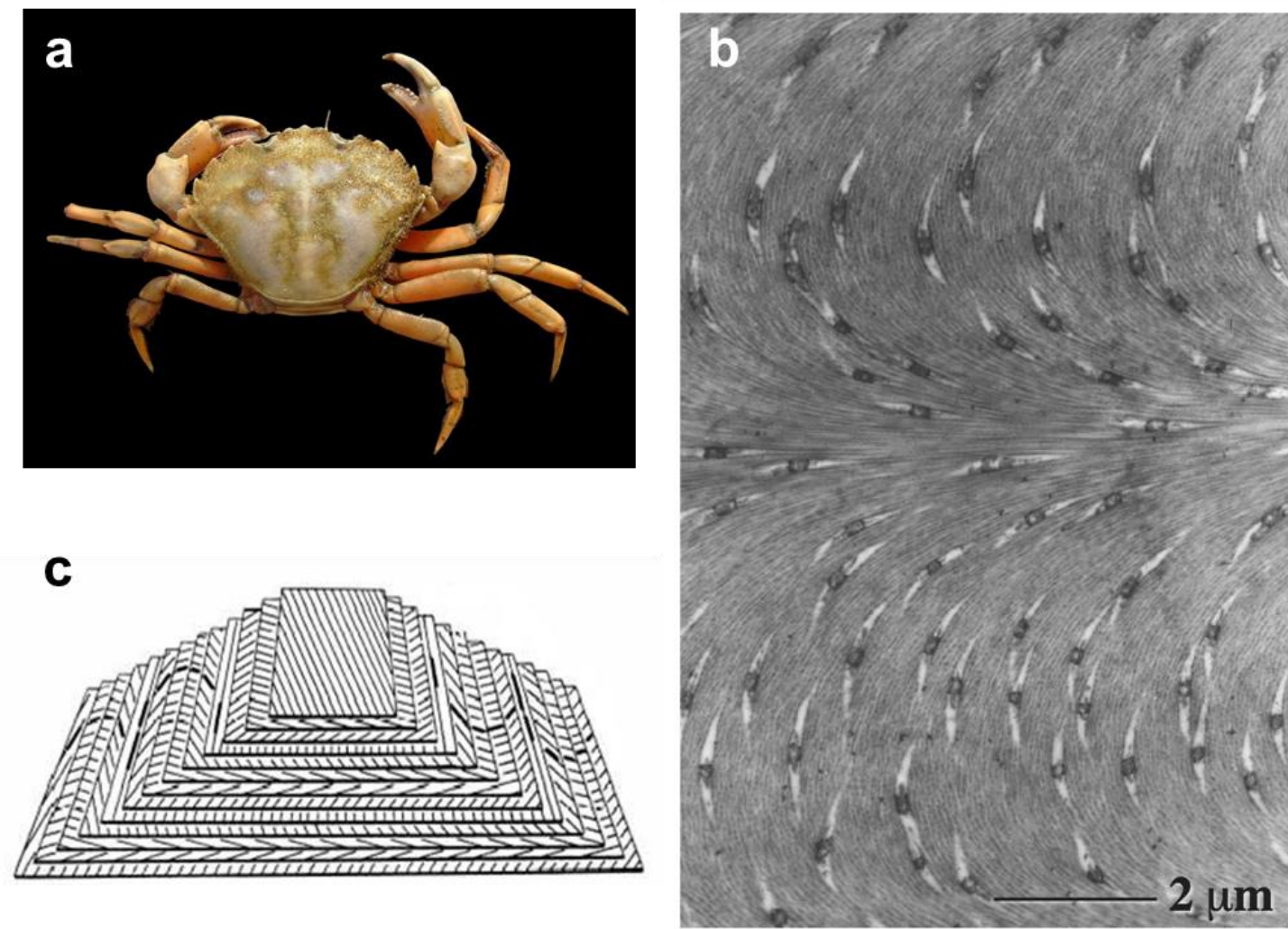

Figure 5. (a) Carcinus mænas crab (Source: Wikimedia Commons). (b) Oblique section of the organic matrix of Carcinus mænas cuticle. The fibrils made of chitin and proteins draw stacked rows of parallel arcs. (c) The twisted plywood model by Bouligand. It represents the cholesteric structure of fibrils in the cuticle of crustaceans and insects. It is formed by a set of superimposed cardboards-the parallel lines symbolize the fibrils - with oblique sections on which the series of nested arcs seen in (b) are clearly visible like the consequence of oblique cuts. The lines change from one plane to the next by a small and constant angle. Let us notice that the concavity of arcs is naturally inversed from one section to another. Reproduced with permission from Ref. [27]. Copyright 1978, Elsevier. 


\subsubsection{Thermal diffusion between layers}

Being thus inspired by biological materials, a pitch gradient may be generated in a cholesteric structure by using glass-forming cholesteric oligomers ${ }^{[116-121]}$ (Figure 6). Two thin cholesteric films with red and blue colors are separately coated onto a glass plate, following which a sandwich cell including spacers is fabricated. The cell is then annealed at a temperature above the glass transition temperature $T_{\mathrm{g}}\left(50^{\circ} \mathrm{C}\right)$. Consequently, a transverse concentration gradient is generated, evidence of which is found by Raman spectrometry. ${ }^{[122]}$ Finally, the material is simply quenched at room temperature (RT) and the gradient is frozen in the glassy solid film. The band-gap features may be tuned simply by varying the annealing time (Figure 7.a). For example, for 25 min annealing time, the transmittance exhibits a broad band gap with a plateau in the visible spectrum. TEM has shown that a regular and continuous transverse pitch gradient is at the origin of the optical response. In the fingerprint texture of the TEM micrograph shown in Figure 7.b, the distance between two bright (or dark) lines is related to the half pitch; the origin of the TEM contrast is discussed in Refs. [123-127]. There is no more interface between pristine films. The periodicity smoothly changes from the red to the blue part of the film.

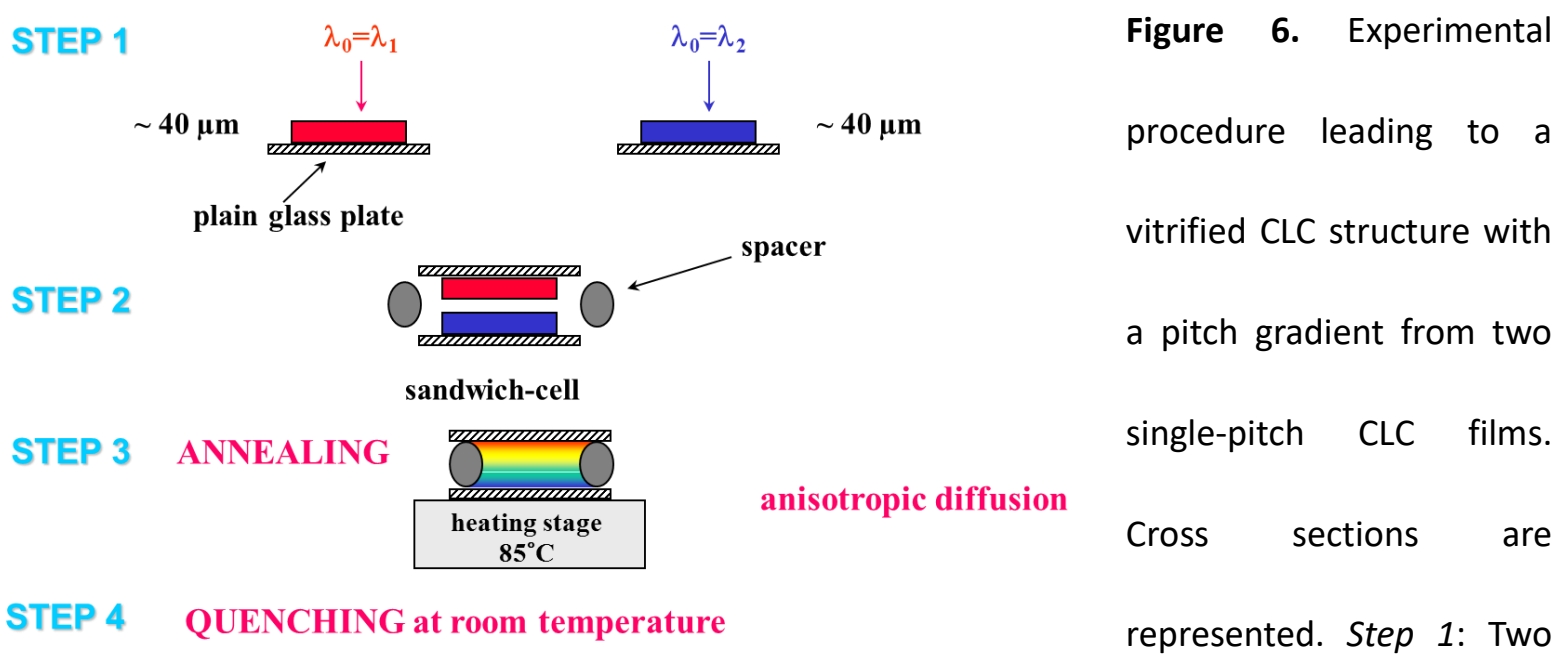


cholesteric films with red and blue colors are coated on separate glass plates. Step 2: A sandwich cell is fabricated with these open films. Step 3: The cell is annealed for a variable time above the glasstransition temperature. A transverse concentration gradient occurs. Step 4: The cell is finally quenched at room temperature. The concentration gradient, and consequently the pitch gradient, is frozen inside a solid film.

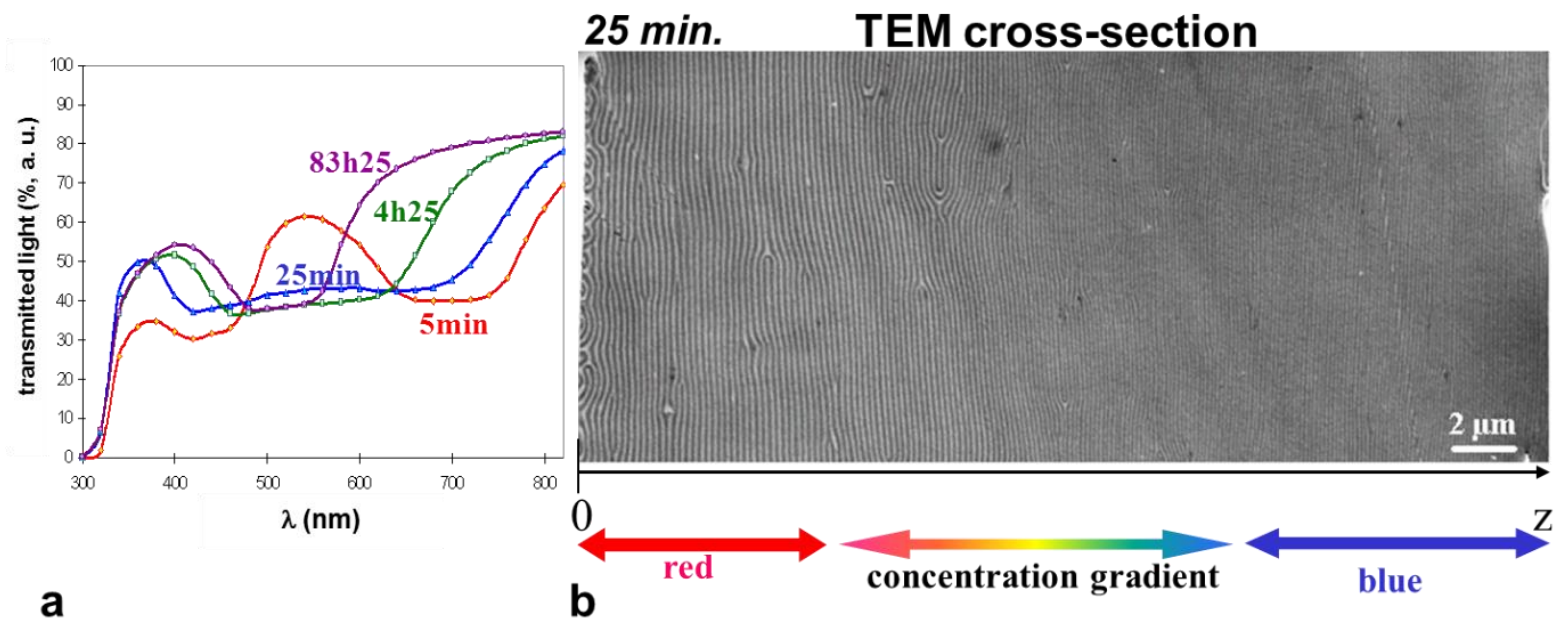

Figure 7. (a) Transmittance of bilayer cholesteric film at different annealing times during Step 3 of Fig.

6. The band gap is tunable by controlling only the annealing time. The change is irreversible. (b) TEM cross-section of the cholesteric film after $25 \mathrm{~min}$ annealing and quenching at room temperature. The distance between two bright (or dark) lines is related to the half pitch. The fingerprint texture exhibits a continuous periodicity gradient.

CLC films in a glassy state have potential applications in the field of high-density optical storage media $^{[31]}$ or tunable solid state lasers. ${ }^{[128]}$ In data storage media, the writing step consists in locally heating by a laser source in a time much less than $1 \mathrm{~s}$, which induces a cholesteric (reflective) to isotropic (transparent) state. The erasing step consists of heating above $T_{\mathrm{g}}$, typically for one second, at which point the material which becomes reflective again. The existence of a pitch gradient allows the 
storage capacity to be increased by providing a film with $n$ storage "layers" without interfaces and tuned to $n$ reflection wavelengths. A detector with laser lines tuned to $n$ wavelengths allows the user to read out the information.

The method given in Ref. [116] has been reproduced with the same materials ${ }^{[129,130]}$ and by using photopolymerization instead of quenching to fix the pitch gradient. ${ }^{[130-133]}$

The method given in Ref. [116] has been adapted to the case of polymer-stabilized CLCs (PSCLCs) ${ }^{[134]}$ in this case, the optical properties are field switchable and three main states are possible: broadband reflection (no field), scattering from a focal-conic polydomain texture, and transparency from a field-untwisted cholesteric structure (nematic state). A PSCLC consists of the in situ formation of an anisotropic polymer within a LC matrix from the polymerization and crosslinking with UV light of a small amount of photoreactive mesogens ( $<10$ wt. typically) ${ }^{[135-137]}$ The LC organization is consequently transferred onto the network morphology. There are two different populations of LCs embedded in the macromolecular network: (i) the thermally stable bound fraction, which corresponds to LC molecules surrounding the polymer surface and in very strong interaction with the polymer; (ii) the free fraction, which corresponds to LC molecules far from the polymer network and with a bulk-like behavior. As a consequence of this template effect, specific optical and electro-optical properties are given to the PSCLC, and these properties depend strongly on the structural characteristics of the polymer network. PSCLCs offer unique properties for color display technologies: bistability, color switching, uniformity of optical properties over a large surface, flexibility, low power consumption, and low cost. ${ }^{[138,139]}$ 


\subsubsection{Control of kinetics of photopolymerization reaction in cholesteric elastomer}

A cholesteric elastomer with a pitch gradient may be fabricated by controlling the kinetics of photopolymerization. ${ }^{[140-145]}$ A cholesteric diacrylate, a nematic monoacrylate, a photo-initiator, and a UV-light-absorbing dye are blended together (Figure 8a). A UV-light-intensity gradient occurs in the transverse direction due to the presence of the dye (Figure $8 \mathbf{b}$ ). At the top of the layer, the polymerization proceeds faster than at the bottom. Since the diacrylate is twice as probable to be incorporated in the polymer, the depletion of the chiral diacrylate near the top generates a concentration gradient; thus, a pitch gradient in the cholesteric structure. The reflection band gap is broadened over the entire visible spectrum (Figure 9). The transfer of the method in Ref. [140] to the case of PSCLCs ${ }^{[75,76,146-148]}$ has given rise to materials that can be switched to the homeotropic transparent state and reverted to the planar reflective state upon removal of the field..$^{[75,76,146]}$

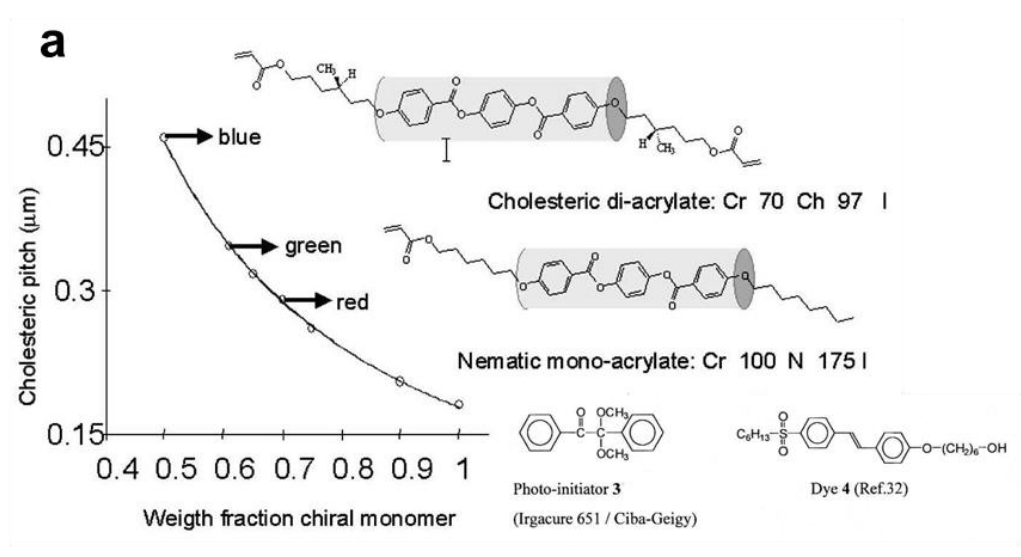

b

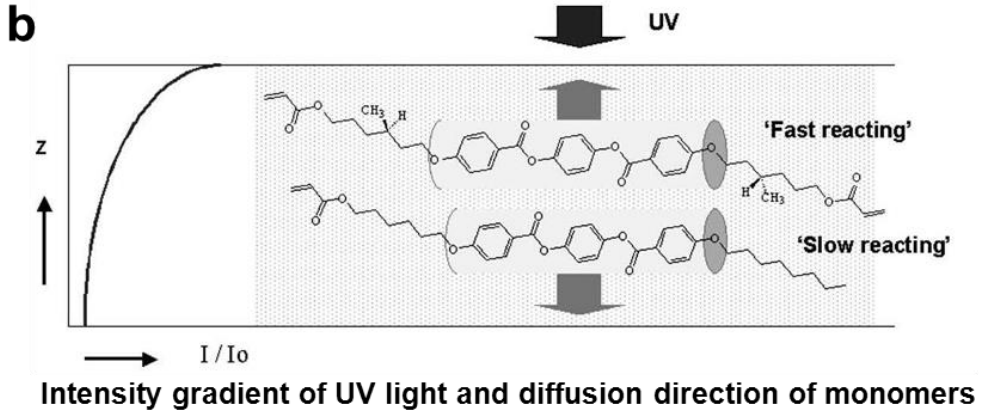

Figure 8. (a) Cholesteric diacrylate, nematic monoacrylate, photo-initiator and UV absorbing dye used in Ref. [140] to fabricate a cholesteric elastomer with a pitch gradient. The dependence of the pitch (and the related reflection color) with the weight fraction in chiral monomers is reported. (b) Representation of 
the gradient of UV intensity in the mixture (left) and direction of diffusion of different monomers during the curing. Reproduced with permission from Ref. [145]. Copyright 2005, Taylor \& Francis Inc.

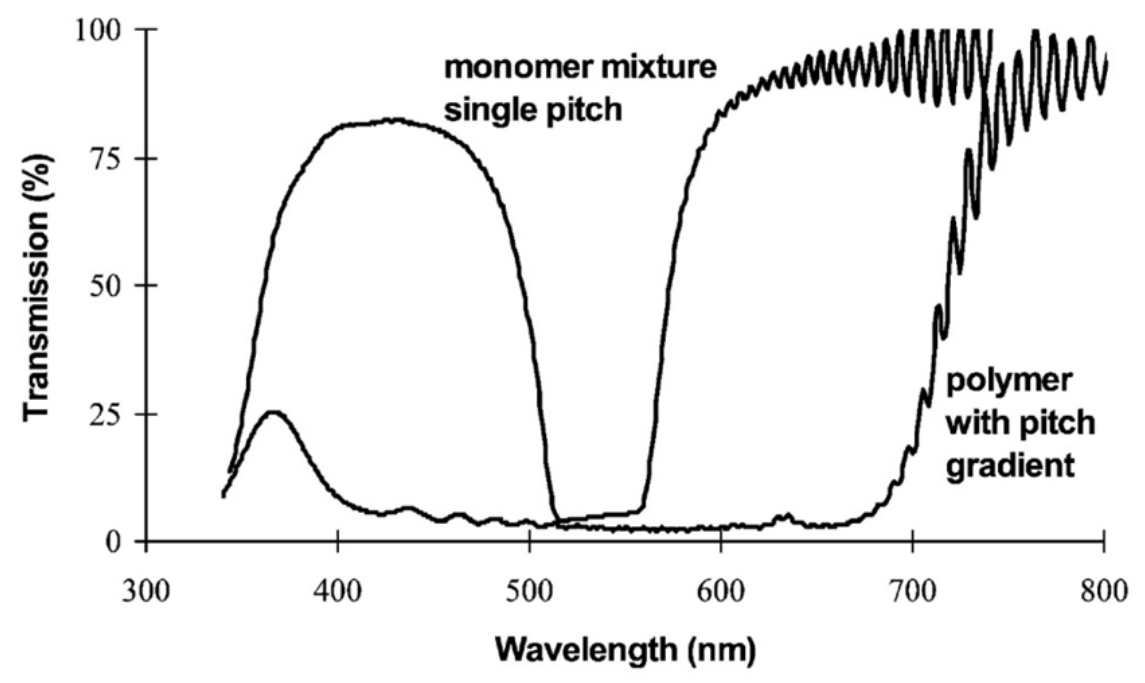

Figure 9. Transmission of right-handed circularly polarized light of a 1:1 mixture of the monomers shown in Fig. 8a before and after curing in the presence of a UV intensity gradient.

Reproduced with permission from Ref. [145]. Copyright 2005, Taylor \& Francis Inc.

Cholesteric elastomers with a pitch gradient have been used to recycle light in LCDs by placing the elastomer foil at the back side of the device ${ }^{[149-153]}$ (Figure 10). The light that is usually absorbed by the rear polarizer goes back to the viewer and, in return, the brightness gain at normal incidence is $40 \%$ to $80 \%$ greater than with only a standard dichroic polarizer.

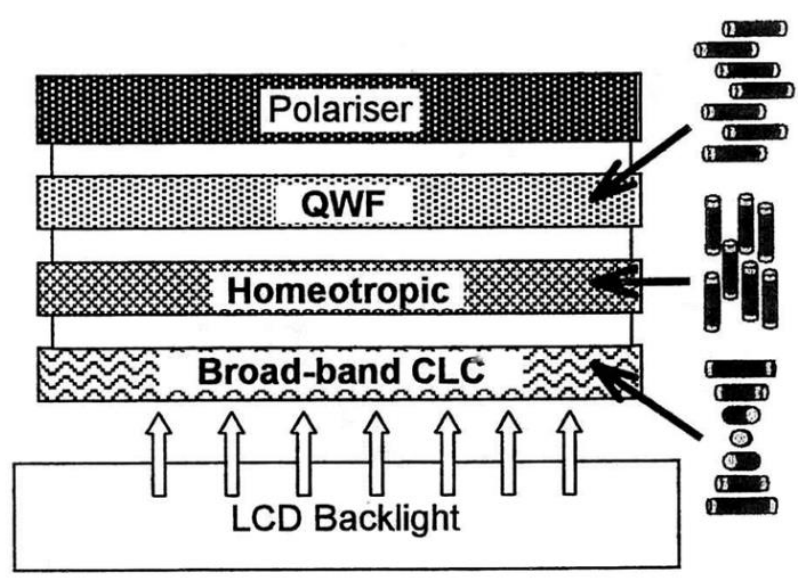

Figure 10. Structure of Transmax@ reflective polarizer. A broadband cholesteric liquid crystal film is combined with a quarter-wave film (QWF) and, optionally, a homeotropic nematic liquid crystal film. When placed between the backlight of the liquid crystal 
display (LCD) and the rear polarizer of the display, most of the light of the polarization state which would ordinarily have been absorbed by the polarizer is recycled by the reflective broadband film. (Courtesy of O. Parri, Merck Chemicals Ltd., Southampton, UK).

Cholesteric elastomers with a pitch gradient have also been doped with a laser dye. ${ }^{[154]}$ The experimental conditions were optimized to fabricate a material with a reflection band that covers the emission peak of the dye and exhibits high degrees of $\mathrm{CP}$ photoluminescence in the blue region.

Investigations related to Ref. [140] have focused on the realization of broadband reflectors by controlling the rate of polymerization in a blend containing a photoreactive LC and nonreactive cholesteric and nematic LCs. ${ }^{[151,155-160]}$ The polymerization rate has to be slower than the diffusion rate of nonreactive molecules. Because the actinic UV light has an exponential intensity distribution due to light absorption, a nonlinear distribution of the polymer material occurs across the film. Close to the layer surface where more segregated achiral LC molecules are accumulated, the pitch becomes longer, and farther from the surface the pitch becomes shorter, hence the formation of a pitch gradient through the layer. For the same layer thickness, the bandwidth of the CLC reflector related to a pitch, which follows an exponential distribution transverse to the layer, is much broader than a linear distribution. ${ }^{[155]}$

\subsubsection{Use of UV-light-absorption properties of LC in PSCLC}

A polarity-sensitive electro-optical response in a NLC-(nonmesogenic) monomer mixture ${ }^{[161]}$ and a polarity-sensitive bistable color effect in a $\operatorname{PSCLC}^{[162]}$ have been described as the consequence of the existence of an asymmetric polymer network, which results in the UV-light-absorbing properties of the LC. In the present topic of broad band gaps, there is an alternative to the introduction of a dye into the 
LC ${ }^{[140]}$ by taking advantage of the natural UV-light-absorbing properties of LC during the fabrication of a PSCLC. ${ }^{[163,164]}$ An example is displayed in Figure 11. Before curing, $\Delta \lambda$ is about $80 \mathrm{~nm}$. Two geometries are chosen for irradiation by UV light: the beam enters one side of the cell only, or both sides. The broadening of the band gap is clearly larger in the former case- $-220 \mathrm{~nm}$ versus $160 \mathrm{~nm}$. To investigate the polymer network morphology, the LC was removed from the PSCLC and the network was embedded in a resin with care taken to preserve its spatial distribution. TEM investigations of cross sections (Figure 12) indicate a network of oriented polymer chains and a polymer gradient from the top to the bottom of the cell, especially when the irradiation conditions are asymmetrical. The network is more concentrated close to the upper side of the cell, which is related to the incoming beam. The broadening of the band gap is due to the polymer gradient. The direct reflectance properties reveal that there is one main reflection peak associated with each side of the cell, and each peak is at the opposite extreme of the visible spectrum. The low reflection wavelength is related to the top of the cell and the high reflection wavelength is related to the bottom. This situation is unexpected because the network-forming material consists of nematic monomers, which means that a longer pitch is expected in the region where the polymer density is largest. This behavior has been discussed in relation to the profile of the photoinduced phase separation between the monomers and the CLC; ${ }^{[164]}$ it appears that, among other parameters, the asymmetry and the slope of the variation of $\Delta \lambda$ with monomer concentration has to be accounted for to explain the distribution of the reflection colors in the volume of PSCLCs with strong network gradients. 


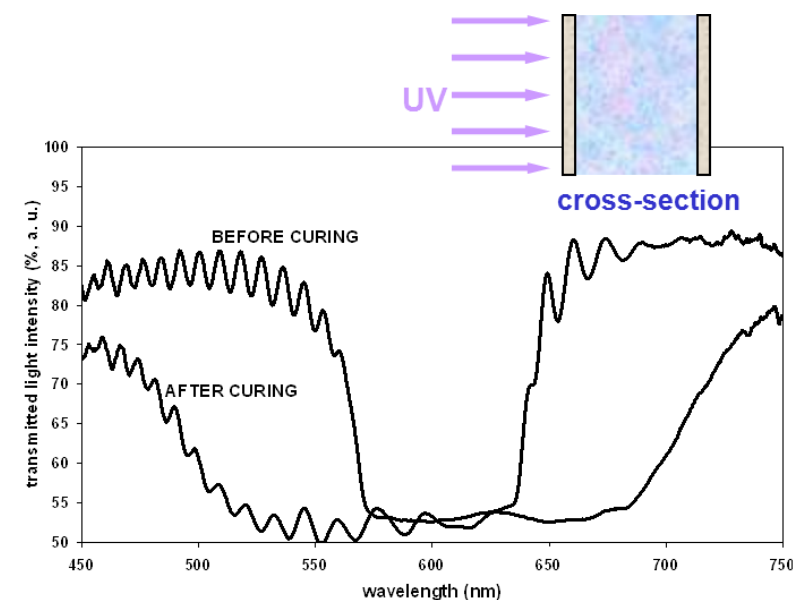

a

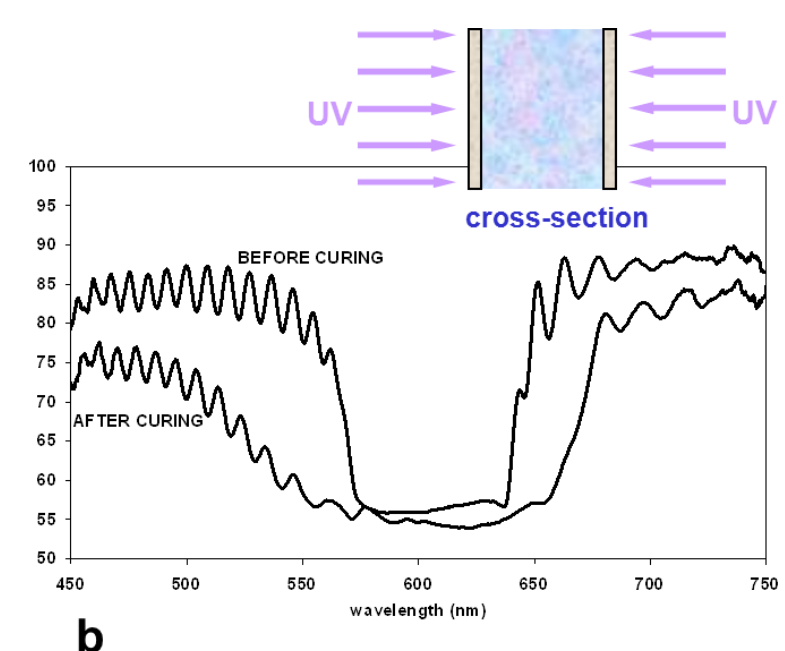

b

Figure 11. Transmittance of a polymer-stabilized cholesteric liquid crystal before and after curing when the cell is irradiated with UV light: (a) from only a single side (asymmetric conditions), and (b) from both sides simultaneously (symmetric conditions). Adapted with permission from Ref. [163]. Copyright 2006, American Institute of Physics.

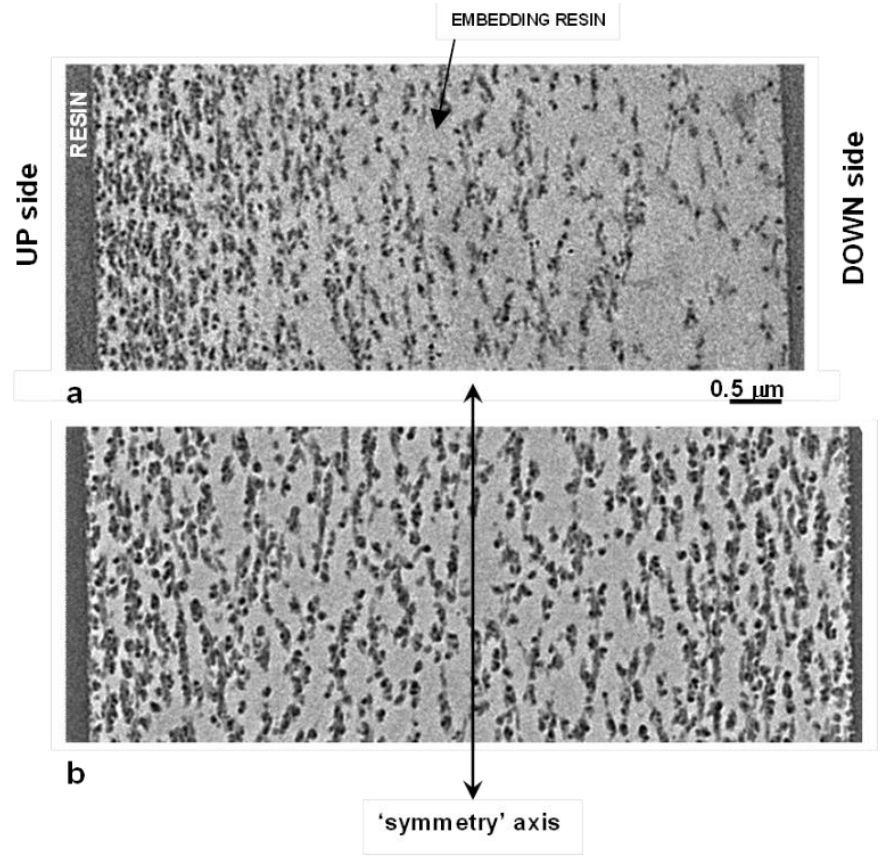

Figure 12. TEM cross sections of polymer network of polymer-stabilized cholesteric liquid crystals whose the transmittance spectra are given in Fig. 11, after removal of the $\mathrm{LC}$ and embedding in a resin matrix. The cell was irradiated under: (a) asymmetric and (b) symmetric conditions. Adapted with permission from Ref. [163]. Copyright 2006, American Institute of Physics. 
In Refs. [165-167], the methodology given in Ref. [163] was reproduced and applied to different CLC blends, which demonstrates the generic nature of the procedure.

Ref. [168] investigates the influence of curing conditions in determining whether a symmetric or nonsymmetric broadening is obtained around the central wavelength $\lambda_{0}$. A nonsymmetric broadening towards the blue is promoted when the curing occurs at very low UV light intensity (a few $\mu \mathrm{W} / \mathrm{cm}^{2}$ at $335 \mathrm{~nm}$ vs. $0.1 \mathrm{~mW} / \mathrm{cm}^{2}$ at $365 \mathrm{~nm}$ ) and for a longer time (typically $1 \mathrm{~h}$ vs. $0.5 \mathrm{~h}$ ).

\subsubsection{Memory effects in PSCLCs}

The broadening of the reflection band gap may be the result of the photopolymerization history, much like the thermal history for a polymer-CLC composite with high concentration in polymer-forming materials ${ }^{[169-171]}$ and PSCLCs. ${ }^{[172-175]}$ The point is to carry out the photopolymerization and the photocrosslinking at the same time that the pitch is changing. If a CLC mixture that exhibits a clearcut thermally-induced pitch variation is chosen, and if the right balance between the color changes and the kinetics of the polymerization process is found, at the end $\Delta \lambda$ is increased by a factor of 3 or 4 over the pristine value. The performances depend on the profile of the pitch variation with temperature, the nature of the monomers (e.g., their flexibility ${ }^{[174]}$, concentration), and the rate of heating or cooling. The thermal process may consist of a continuous ramp between two target temperatures ${ }^{[169,172]}$ or the curing may occur at several temperatures (discrete process) ${ }^{[173-175]}$ that correspond to different cholesteric colors. The network has been built into several steps and, because of the template effect, its morphology includes different twisted structures that arise in the blend as the curing proceeds. These structural memory effects are irreversible. In consequence, the structure of the bound CLC fractions include different helical pitches. Each region gives rise to a color and $\Delta \lambda$ is, in return, broadened when 
the material comes back to RT. Here also the PSCLC can be switched between broadband reflective, scattering, and transparent states by subjecting the layer to an electric field.

\subsubsection{Photoracemization broadening of reflection band gap}

The band gap can be broadened as a direct consequence of a spatially modulated photoracemization reaction. ${ }^{[176,177]}$ Glass-forming CLCs are blended with a chiral dopant with a high HTP and that is susceptible to photoracemization (i.e., CLC to NLC phase conversion). A thermo- and photoinduced racemization is generated in a layer of the blend. The $(\mathrm{R})$-enantiomer near the irradiated surface is converted to the (S)-enantiomer as the photochemical process is initiated by UV light, thereby setting up a counter-diffusion of two enantiomers across the layer as stipulated by the conservation of mass. As a consequence, a pitch gradient is generated across the layer, as shown by atomic force microscopy (AFM). The gradient is frozen inside a solid film by simply quenching the material below the glass transition temperature. At RT, the material reflects wavelengths greater than $400 \mathrm{~nm}$ (Figure 13).

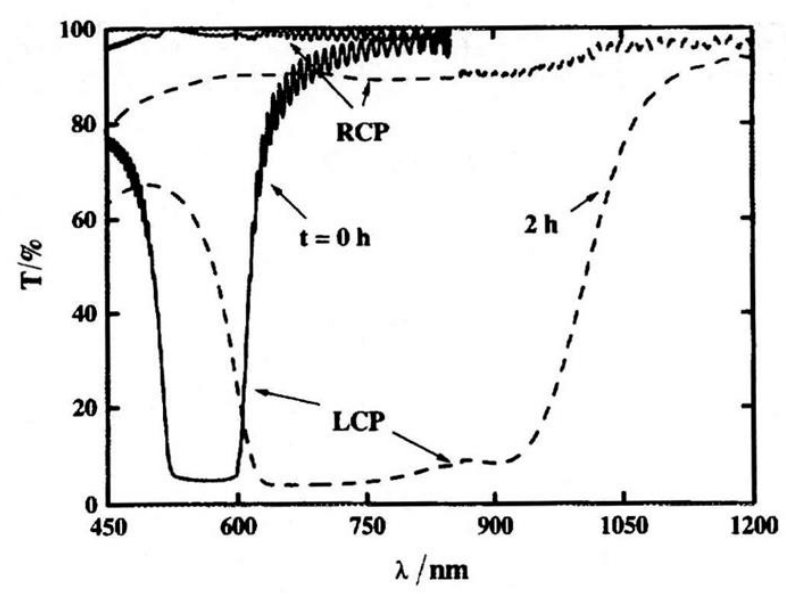

Figure 13. Transmittance of glassy cholesteric liquid crystal films before and after photoracemization $\left(140\right.$ @W/ $/ \mathrm{cm}^{2} @ 334$ nm. $T=$ $100{ }^{\circ} \mathrm{C}$. Curing time $=2 \mathrm{~h}$ ) measured when the incident light is right- or left-handed circularly polarized (RCP and LCP). The solid (dashed) curve corresponds to the response of the pristine (photoracemized) film. Reproduced with permission from Ref. [176]. Copyright 1999, WileyVCH Verlag GmbH \& Co. KGaA, Weinheim. 


\subsubsection{Photoisomerization broadening of reflection band gap}

The broadening of the band gap by photoisomerization ${ }^{[178]}$ is an alternative route to the method given in Ref. [140]. A photoisomerizable chiral copolymer (with menthone units, known for their large UVinduced changes of HTP) is blended with a NLC and a UV absorber. The absorber creates a gradient in UV intensity throughout the layer; the isomerization is then faster at the top of the layer, the HTP presents a transverse gradient in the layer and, consequently, a cholesteric structure with a transverse pitch gradient. After only $10 \mathrm{~min}$ of exposure to UV light, the band gap may span the entire visible spectrum. Due to the diffusion of the compounds, the pitch gradient gradually disappears during storage. However, the properties can be frozen by quenching the layer below the glass transition temperature when wide-band reflectors are prepared from pure copolymers.

\subsubsection{Use of inorganic template with graded pitch}

A porous inorganic network of helical columns of $\mathrm{SiO}_{2}$ with a pitch equal to $410 \mathrm{~nm}$ is deposited onto a glass substrate by using the glancing angle deposition (GLAD) technique ${ }^{[179]}$ (Figure 14). A lowmolar-mass NLC infiltrated by capillarity inside this chiral film adopts a chiral structure. The composite film exhibits optical activity and CP reflection like a CLC. ${ }^{[180,181]}$ When a network is fabricated with a pitch linearly graded from 500 to $350 \mathrm{~nm}$ from the top to the bottom of the layer, the NLC adopts a twisted structure with a gradient pitch and, in return, the material reflects a broad bandwidth of light. ${ }^{[182]}$ The reversible electro-optical switching of the LC component in the hybrid film has been demonstrated. ${ }^{[182]}$ 

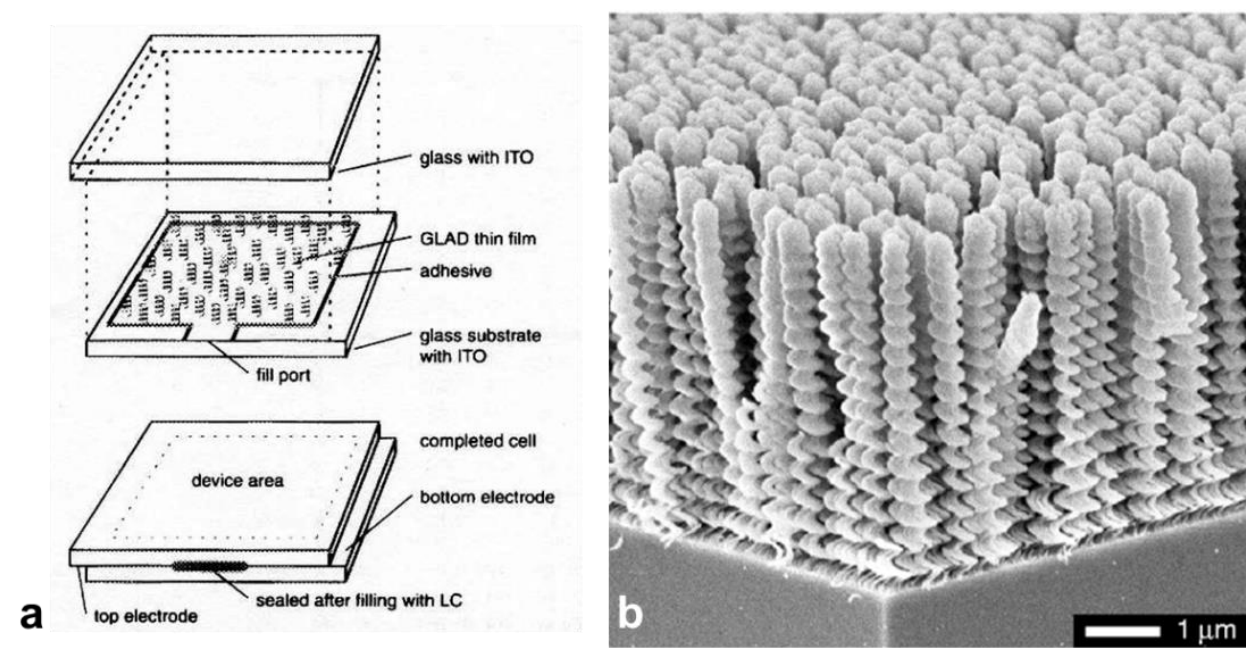

Figure 14. (a) Structure of a sandwich cell with a porous chiral film fabricated according to the glancing angle deposition (GLAD) technique. A GLAD film is deposited on an ITO-coated glass substrate (1 inch square). A second substrate is used to sandwich the GLAD film. The edges of the structure are sealed with resin, leaving a small port for liquid-crystal filling. Reproduced with permission from Ref. [182]. Copyright 2000, Taylor \& Francis Ltd. (b) SEM micrograph of a GLAD film of MgF 2 on glass with fifteen helical turns of the cholesteric structure (pitch $~ 350 \mathrm{~nm}$ ). Reproduced with permission from Ref. [181]. Copyright 1999, Nature Publishing Group.

Theoretical approaches to the optics of CLCs with a spatially varying pitch may be found in Refs. [183-189]. Several of them use the finite element method and the Berreman's $4 \times 4$ matrix method to simulate reflection or transmission spectra.

\section{Going Beyond the Reflectance Limit}

The topic of cholesteric structures exhibiting double-handed CP reflection bands is a more recent research subject. 
3.1. Multilayer system: from cuticle of Plusiotis resplendens to polymer-based composite materials

To our knowledge, Plusiotis resplendens (also called Chrysina resplendens) is the only beetle whose cuticle reflection properties do not obey the polarization-selectivity rule. ${ }^{[100,190]}$ The chitin-made cuticle is a three-layer system (Figure 15) which exhibits, from the top to the bottom of the shell: a lefthanded cholesteric structure, a half-wave-plate nematic structure, and again a left-handed helix. Under unpolarized light conditions, LHCP is reflected by the first layer whereas RHCP light is transmitted; after passing through the half-wave plate, RHCP light is converted to LHCP light, which is reflected by the third layer; it finally emerges from the cuticle as RHCP light after passing back through the half-wave plate again. Interestingly, a supplementary function of the half-wave plate is to reduce multiple internal reflections. Such a dual CP reflector operates between 520 and $640 \mathrm{~nm}$. A Muellermatrix characterization of the reflection properties of Plusiotis resplendens may be found in Ref. [191].

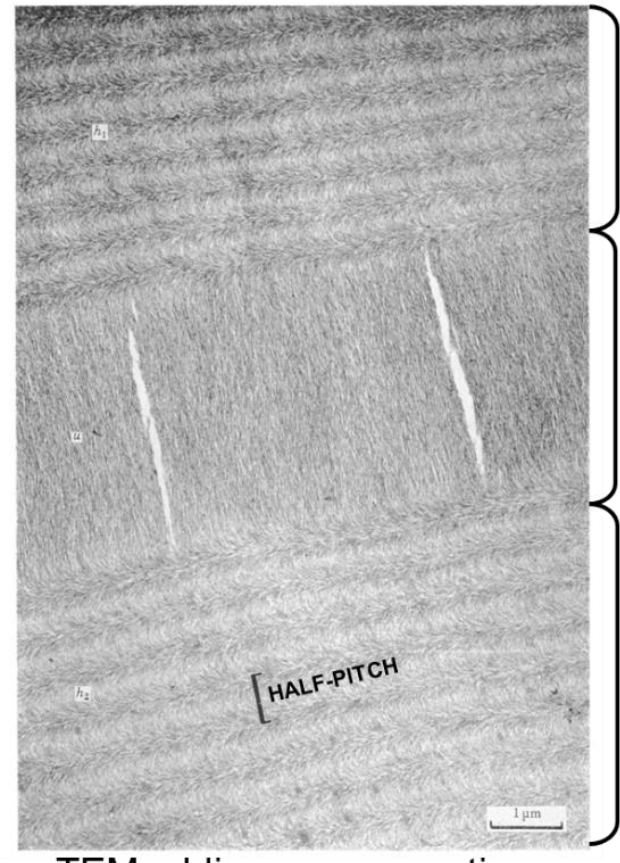

TEM, oblique cross-section

\section{LEFT-HANDED HELIX}

HALF-WAVE PLATE

unidirectional layer

LEFT-HANDED HELIX

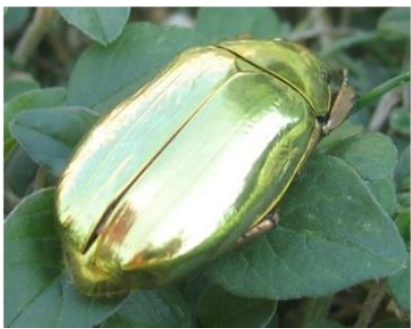

Figure 15. TEM micrograph of portion of oblique section of cuticle of Plusiotis resplendens including unidirectional layer and adjacent lefthanded helical layers. The parabolic patterning is typical of an oblique section (see Fig. 5 with detailed 
caption). Notice that the pattern is similar above and below the unidirectional layer, indicating that the sense of the twist does not change. The layering periodicity is related to the half pitch and is pinpointed with a black bar. Adapted with permission from Ref. [190]. Copyright 1971, The Royal Society. Inset: Plusiotis resplendens beetle (Copyright M. Mitov, CNRS-CEMES).

In what way do the remarkable optical properties of Plusiotis resplendens aid this beetle in its everyday life and survival? This question would be a very interesting research subject combining optics and the physiology of insect eyes, for example, and the answer is still pending.

Replications of the cuticle of Plusiotis resplendens can be found in Ref. [192], and Refs. [193,194] provide the same with the addition of lasing effects when the NLC layer is doped with a laser dye. More classically, it is also possible to fabricate a bilayer system from cholesteric structures with the same pitch but inverse helicities. ${ }^{[192,195-197]}$

\subsection{Use of CLC with thermally induced inversion of helicity in PSCLCs}

The goal is to fabricate a PSCLC monolayer with an original structure in which both handed helices coexist in the IR spectrum. A CLC mixture that exhibits a thermally-induced helicity inversion can be chosen for this purpose. ${ }^{[198-202]}$ Two general explanations for helix inversion behavior have been suggested. In one, the statistical distribution of the many molecular conformations shifts with temperature. ${ }^{[203,204]}$ In the other, the competition between the different temperature dependencies and opposite chiralities of multiple chiral centers causes the helix inversion. ${ }^{[205,206]}$ Experimental support for the first explanation comes from NLCs doped with chiral dopants, ${ }^{[207,208]}$ whereas results verifying the second explanation use diastereomeric LC compounds. ${ }^{[209,210]}$ 
Basically, the idea is to fabricate the PSCLC when the helix is right-handed and has a pitch $p_{0}$ (at temperature $T_{2}$ ) and then to cool the material below the critical temperature $T_{\mathrm{c}}$ at which the helicity inversion occurs until the temperature $T_{1}$ at which the cholesteric structure of the free fraction has a pitch close to $p_{0}$, but is left-handed (Figure 16a). At $T_{1}$, whatever the polarization of the incident light, the reflectance exceeds the limit of 50\% (Figure 16b) - up to $72 \%$ in the example given in Ref. [198] when the incident light is unpolarized. The polarization-selectivity rule is thus no longer valid.
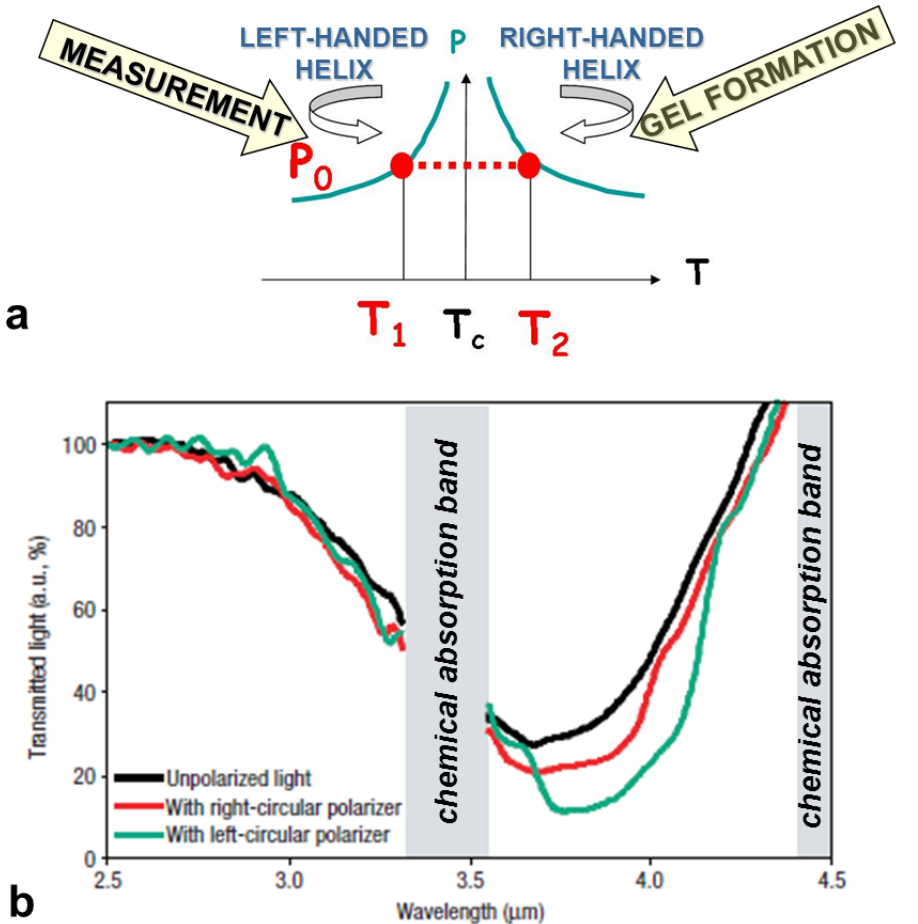

Figure 16. (a) Representation of fabrication procedure of a polymerstabilized cholesteric liquid crystalor gel-layer which exhibits both helicity senses. The gel formation occurs at a temperature $T_{2}$ for which the cholesteric structure of the mixture has a pitch equal to $p_{0}$ and is right handed. The measurement is done at the temperature $T_{1}$ for which the free fraction of the gel exhibits a cholesteric structure that is left handed with a pitch close to $p_{0}$. (b) Transmittance of the gel when the incident light is unpolarized or when a left- or right-handed circular polarizer is introduced into the light beam. Whatever the polarization of the incident light, the reflectance of the cholesteric layer exceeds $50 \%$. Reproduced with permission from Ref. [198]. Copyright 2006, Nature Publishing Group. 
When investigated by SEM, the polymer structure exhibits stacked rows of parallel arcs, which are polymer fibrils. These patterns are characteristic of a cholesteric arrangement when the material has been cut in a direction oblique to the helical axis. They can be seen as the synthetic version of the chitin-made arced structures observed in the cuticle of arthropods, which are related to the twisted plywood model. ${ }^{[23]}$ Here the polymer network acts as a thermally stable internal memory of the helix characteristics (pitch and helicity) at the moment of PSCLC fabrication. The bound fraction is stabilized at $T_{2}$ : the pitch and the helicity of the related cholesteric structure will not change with temperature. The pitch and the helicity of the free fraction are free to change: at $T_{1}$, the cholesteric structure of the free fraction is left handed and has a pitch close to $p_{0}$. Every fraction gives rise to a reflection band, and the PSCLC is equipped with two CPL reflection bands in the same notch and inverse senses.

The right monomer concentration is necessary to get the basic result. ${ }^{[201]}$ If the concentration is above a given threshold, the structural characteristics of the composite material become fully frozen in a single twist sense. If the concentration is too low, the system behaves like the LC alone. In between, at $6.2 \mathrm{wt} \%$ for example, the bell-like curve is the signature of the desired behavior (Figure 17).

To avoid introducing tremendous light scattering into the reflection properties, it is essential to cool the material very slowly from the preparation temperature $\left(T_{2}\right)$ to the operating temperature $\left(T_{1}\right){ }^{[199]}$ An especially efficient alternative solution consists of subjecting the cell to an electric field at the same time that it is cooled from $T_{2}$ to $T_{1} \cdot{ }^{[201]} \mathrm{A}$ very regular planar texture is promoted all along the thermal process, provided that a CLC mixture with a negative dielectric anisotropy has been chosen.

It has been shown that the dual reflection band of a PSCLC can be conserved at RT whatever the polymorphism of the blend. ${ }^{[202]}$ The cell has to be quickly quenched in liquid nitrogen from $T_{2}$ to RT. The resulting property comes from a double memory effect: the bound fraction gives rise to a RHCP band as a consequence of the template effect found in PSLCs; the free fraction is fixed in an 
undercooled state and gives rise to the LHCP band. For cells stored at RT and without particular caution, the optical properties are stable for years.

When a UV absorber is introduced in the blend, the PSCLC exhibits a strong structural discontinuity and two distinct reflection bands with inverse circular polarizations appear. ${ }^{[211]}$ The origin of this property and the related structure are very different than in the previous case: the system behaves like a biphasic material with two CLC slabs—one corresponds to a polymer-rich region and the other to a polymer-poor region that is field-switchable.

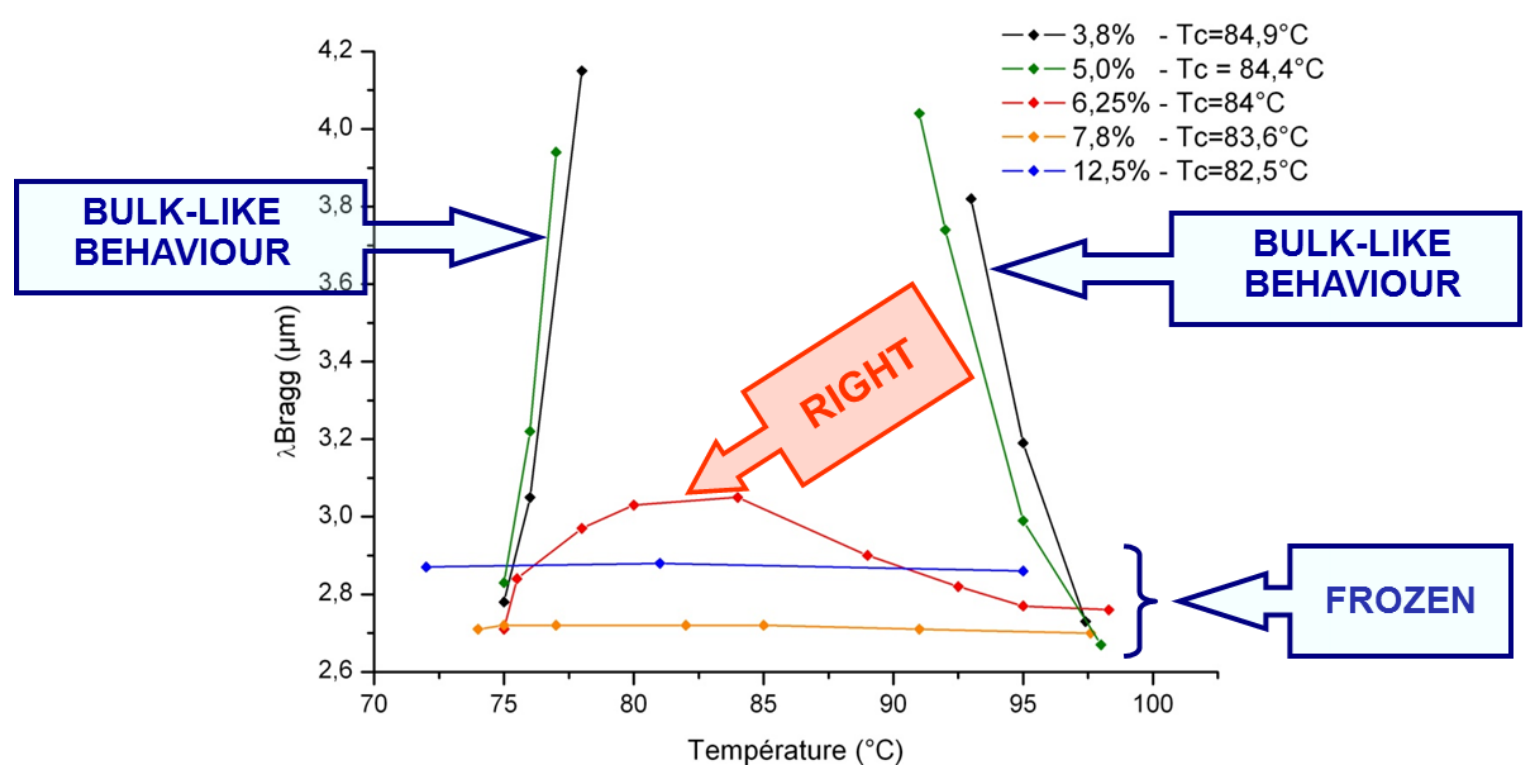

Figure 17. Mean reflection wavelength as a function of temperature and monomer concentration for a polymer-stabilized cholesteric liquid crystal (PSCLC), which exhibits a thermally induced inversion of helicity. The critical temperature $T_{\mathrm{C}}$ at which the inversion occurs is mentioned for each concentration. If the monomer concentration is too low (i.e., 3.8 or $5.0 \mathrm{wt} \%)$, the optical behavior of the PSCLC is similar to that of the mixture before curing. If it is too high (i.e., 7.8 or $12.5 \mathrm{wt} \%$ ), the optical behavior of the PSCLC does not change with temperature; the material behaves as if it were frozen by a full polymerization and crosslinking. The bell-like curve shown when the concentration is 
equal to $6.25 \mathrm{wt} \%$ is the behavior to target if a PSCLC reflecting both left- and right-handed circularly polarized bands is desired. Redrawn from Ref. [201].

\subsection{Wash-out/refill techniques}

The basic procedure in wash-out/refill techniques ${ }^{[60,62,212-214]}$ begins with a polymer network being fabricated in situ in a left-handed CLC mixture (Figure 18). Next, the low-molar-mass CLC is removed from the cell by immersing it in cyclohexane. The porous network is then filled with a righthanded CLC. The reflectance of unpolarized light exceeds $50 \%$ because LH and RH CP bands are reflected from the bound and free fractions, respectively.

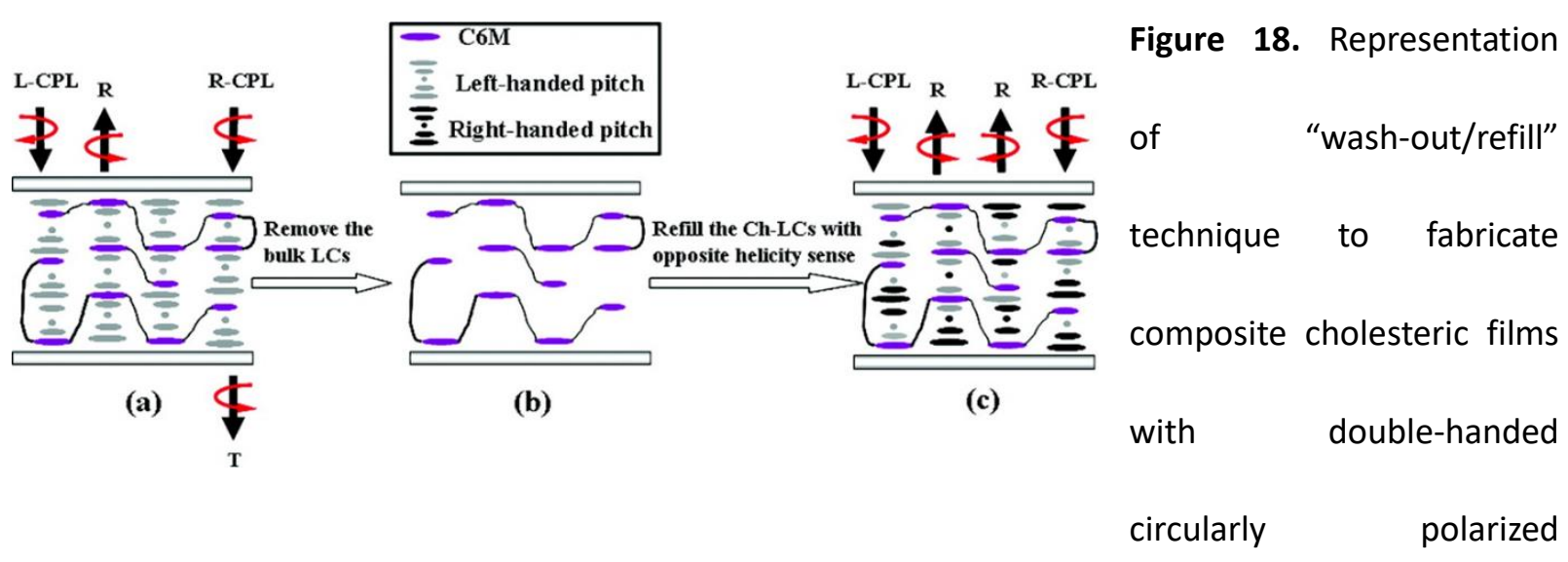

reflection bands. (a) The polymer-stabilized cholesteric liquid crystal (PSCLC) is fabricated when the helical structure is left handed with a given pitch. (b) The CLC is removed by immersing the cell in the proper solvent. (c) The porous helical polymer network is filled with a low-molar-mass CLC that exhibits a cholesteric structure with the same pitch as that of the CLC in (a) but with a right-handed sense. Reproduced with permission from Ref. [213]. Copyright 2009, American Chemical Society. 
Such a technique may allow dynamic control of the reflection band ${ }^{[60,62,215,216]}$ A peculiar variation of the method is given in Ref. [216] (Figure 19a), wherein a polymer network is fabricated in situ in a right-handed CLC mixture. The photo-initiator was embedded in one of the two alignment layers coated on surfaces of the sandwich glass cell so that the network became localized close to one surface. The low-molar-mass CLC was removed from the cell by immersing it in cyclohexane. The porous network was then filled with a LC that presents a chiral smectic A to chiral nematic phase transition at $27{ }^{\circ} \mathrm{C}$. The reflectance of unpolarized light exceeds $50 \%$ at $33{ }^{\circ} \mathrm{C}$ because $\mathrm{RH}$ and $\mathrm{LH} \mathrm{CP}$ bands are reflected from the bound and free fractions, respectively (Figure 19b). The localization of the network close to one surface serves to better preserve the network structure during the drying process and allows for easier refilling, in order to promote a polymer-free surface.

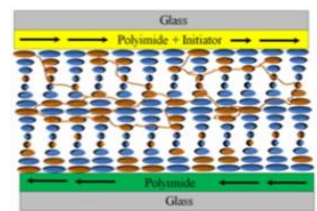

1

a

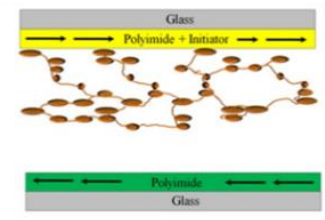

2

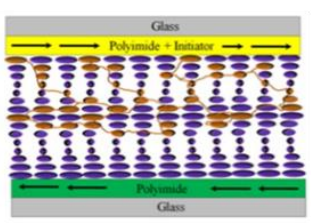

3

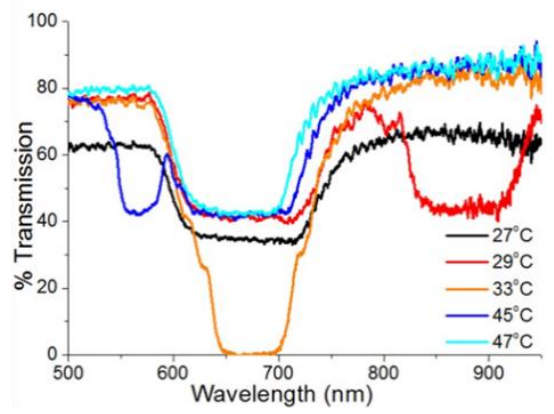

b

Figure 19. (a) Representation of process to fabricate composite cholesteric films with double-handed circularly polarized reflection bands. Step 1: The polymer network is fabricated in situ in a righthanded cholesteric mixture. Because the photo-initiator was embedded in one of the two alignments layers coated on the surfaces of the sandwich glass cell, the network is localized close to one surface. Step 2: The low-molar-mass cholesteric liquid crystal is removed from the cell by immersing it in the proper solvent. Step 3: The porous helical polymer network is filled with a low-molar-mass CLC that exhibits a chiral smectic A to chiral nematic phase transition at $27^{\circ} \mathrm{C}$. (b) Related transmission spectra 
at different temperatures. The reflectance goes beyond $50 \%$ at $33{ }^{\circ} \mathrm{C}$ because right-handed and lefthanded circularly polarized bands are reflected in the same band gap from, respectively, bound and free fractions of liquid crystal molecules. Reproduced with permission from Ref. [216]. Copyright 2011, Wiley-VCH Verlag GmbH \& Co. KGaA, Weinheim.

\subsection{Theoretical approaches}

Theoretical and numerical treatments of broad band circular polarizers are very recent, even outside of the present field; consider, for example, helical gold metamaterials operating in the IR or visible spectrum. ${ }^{[40,217,218]}$

CLC structures that reflect both circular polarizations at normal incidence have been suggested. ${ }^{[219]}$ The director of the chiral nematic structure does not rotate uniformly around the helical axis but oscillates about a certain direction following a predetermined modulation. Both sinusoidal and rectangular modulations of the twist profile have been considered.

The scenario of a cholesteric elastomer immersed in a racemic solvent is considered in Refs. [220222]. As in Ref. [85], the elastomer slab exhibits nested reflection band gaps like a broad LHCP band that contains a thinner RHCP band. The result depends on the volume fraction of chiral molecules in the solvent with a defined handedness and that would be preferably absorbed in the distorted network of the cholesteric elastomer. The system might function as a filter with chemically controlled bandwidth and reflectance. Still on the subject of distorted elastomers, it has been suggested that a chiral twist defect inserted in a cholesteric elastomer gives rise to CP localized modes of both handedness. ${ }^{[23]}$ This defect enhances the resonant mode amplitude whose the handedness is opposite that of the helix for high crosslinking density (this parameter is related to the chiral parameter order), 
whereas the same mode is decoupled with the defect and the resonant mode disappears for low density.

The case of the imbrication of double-handed cholesteric structures described in Ref. [198] has been addressed with numerical simulations based on a stochastic approach. ${ }^{[224]}$ The optical properties are approached by the finite-difference time-domain (FDTD) method. The accuracy of the numerical simulations is verified by direct comparison of indicative examples with the Berreman's $4 \times 4$ matrix method. The realistic case of randomly interlaced cholesteric domains with inverse helicities is considered. The theoretical model is generalized to the case of single-layer PSCLCs. Good agreement is found between experimental and simulated spectra, which demonstrate hyper-reflective properties.

\section{Summary and Outlook}

In summary, both reflection limits of CLCs may be exceeded by choosing one or several of the following experimental strategies:

- Stacking layers. The sum of properties of the individual layers provide the property of the final material.

- Driving a thermally induced diffusion in a bilayer to generate a pitch gradient. The gradient is then fixed by quenching if glass-forming LCs are chosen, or by polymerization and crosslinking if photoreactive LC monomers are chosen. In the latter case, the final material is a solid elastomer (passive material) when all the molecules are photoreactive or a fieldswitchable PSLC (active material) when a few percent of reactive mesogens are blended with a low-molar-mass LC.

- Generating memory effects. As a result of a temperature change or an external stimulus, the polymerization and the crosslinking reactions occur at the same time as the pitch and/or the 
helicity sense changes. The stimulus may be an electric field, radiation, or mechanical stress. Alternatively, the preparation temperature and the operating temperature can be different; that is, the polymerization and the crosslinking reactions occur when the cholesteric structure has a fixed pitch and helicity, and the optical properties of the final material are used at another temperature — which may include room temperature — where the structure has a different pitch or helicity.

- Generating a pitch gradient by photopolymerization in itself. A UV-light-absorbing dye or LC is used. Monomers with different reactivities and chiralities may be used. A photoracemization or photoisomerization reaction may also occur.

- Using a template, like an inorganic template (present ab initio) or a polymer template (built in situ).

The above list is given without hierarchy. The choice of a peculiar procedure, or combination of procedures, strongly depends on the fundamental question to be addressed or the application that is targeted.

The research into novel cholesteric architectures gives rise to fresh and stimulating research topics. It is based on the fundamental question of the relationship between the chirality of the structure - twist sense and pitch (linearly changing or not, exhibiting a gradient or, on the contrary, distributed at random in the volume of the material) — and the molecular chirality (or the nature of a mixture of different chiral molecules). This question is still largely open.

For applications, the solution to choose depends notably on (i) the desired function, (ii) the device in which the layer is implemented, and (iii) the fabrication costs for mass production. We give a brief example to illustrate each consideration. (i) A passive (active) layer is required if a permanent (fieldswitchable) broadband reflection is desired. The fabrication procedure associated with the formation a solid layer can be very specific to this basic situation. A polymer network, with a thermally stable 
nonreversible structure, or a quenched glassy film (especially adapted for reversible optical recording) will be chosen. A solid film may be coated on a single surface, confined between surfaces (rigid or flexible as well), or may even constitute a free-standing film. A PSCLC, or cholesteric gel, may exhibit electro-optical properties. Broad band reflecting, scattering, and transparent states are available; they depend of the field amplitude and the addressing scheme. (ii) The case of a layer with an asymmetric structure is especially interesting for innovative technologies such as smart reflective windows. A window is inherently an asymmetric object; solar energy always enters the room from the same side of the panel. The relationship between the propagation of light in a CLC with an asymmetric structure from the top to the bottom of the layer has to be thoroughly investigated to optimize the optical properties. (iii) We may expect that methods requiring the removal of the LC from a gel can present disadvantages in a production process. Such processes need clear-cut criteria to determine if the LC has been fully removed, and they can increase the production costs by invoking additional manipulations. Seen another way, some flexibility may be gained with respect to working temperatures when RT materials are included. However, procedures that can manage a single layer or a single device from the beginning to the end of the process and that lead to the broadening of the reflection band gap may be preferred to multilayer systems or procedures that include a swelling and deswelling of a gel layer, for example.

The research on LCs is fascinating because it provides natural links between a variety of disciplines in soft matter science ${ }^{[225]}$ and beyond (including biology, chemistry, materials science, mathematics, geometry, physics, and technology)—and because it often requires making a continuous description of the structure from the nanometer scale to the macroscopic scale. The subject of CLCs with a broad reflection band provides an excellent illustration of this claim by raising questions, sometimes unsolved, about such things as the morphogenesis of biological tissues, the structural coloration of arthropods for biological functions [e.g., the dispatch of information (recognition, camouflage, and 
other function not yet elucidated), protection against radiation (e.g., to avoid overheating), and its role in evolutionary processes], the role in living matter of structures with a graded pitch, the relationship between structural chirality and molecular chirality, and the impact of structural chirality on the basic properties of reflection and how this structure evolves when the chiral material is subjected to a field. These CLCs also have potential for use in challenging technological applications, not yet available in everyday life, such as intelligent reflective windows for energy efficiency and for dynamic solar control.

[1] G. Friedel, Ann. Phys. 1922, 18, 273.

[2] H. Kelker, Mol. Cryst. Liq. Cryst. 1973, 21, 1.

[3] I. Abdulhalim, Optik 2000, 111, 65.

[4] I. Abdulhalim, Appl. Optics 2008, 47, 2008.

[5] S. Pieraccini, S. Masiero, A. Ferrarini, G. P. Spada, Chem. Soc. Rev. 2011, 40, 258.

[6] $e e$ is used to quantify the efficiency of an asymmetric synthesis. Although enantiomeric excess values cover a range from $-100 \%$ to $+100 \%$, most of time the absolute value $|e e|$ of $e e$ is reported. ee $(\%)=100 \times([R]-[S]) /([R]+[S])$ where $[R]$ and $[S]$ are the respective fractions in $\mathrm{R}$ and $\mathrm{S}$ enantiomers. When the chiral dopant is solely a $\mathrm{R}$ or $\mathrm{S}$ enantiomer: $|e e|=1$. See Ref. [7] for a review on the subject.

[7] D. Leung, S. O. Kang, E. V. Anslyn, Chem. Soc. Rev. 2012, 41, 448.

[8] H.-G. Kuball, T. Höfer, in Chirality in Liquid Crystals (Eds: H.-S. Kitzerow, C. Bahr), Springer-Verlag, New York, USA 2001, Ch. 3.

[9] H. Stegemeyer, H. Finkelmann, Chem. Phys. Lett. 1973, 23, 227.

[10] H. Hanson, A. J. Dekker, F. van der Woude, J. Chem. Phys. 1975, 62, 1941.

[11] Y. Bouligand, Ann. Chim. Sci. Mat. 2004, 29, 83. 
[12] Y. Bouligand, Solid State Physics Suppl. 1978, 14, 259.

[13] Y. Bouligand, C. R. Chimie 2008, 11, 281.

[14] D. M. Small, Surface Chemistry of Biological Systems, (Ed: M. Blank), Plenum, New York, USA 1970, 55.

[15] Y. Bouligand, M.-O. Soyer, S. Puiseux-Dao, Chromosoma 1968, 24, 251.

[16] F. Livolant, A. Leforestier, Prog. Polym. Sci. 1996, 21, 1115.

[17] D. Rey, Soft Matter 2010, 6, 3402.

[18] D. G. Gray, Carbohyd. Polym. 1994, 25, 277.

[19] I. W. Hamley, Soft Matter 2010, 6, 1863.

[20] R. L. Trelstad, Developmental Biology 1982, 92, 133.

[21] M. M. Giraud-Guille, Calcif. Tissue Int. 1988, 42, 167.

[22] M. M. Giraud, J. Castanet, F. J. Meunier, Y. Bouligand, Tissue and Cell 1978, 10, 671.

[23] Y. Bouligand, C. R. Acad. Sc. Paris Sér. D 1965, 261, 3665.

[24] C. Neville, S. Caveney, Biol. Rev. 1969, 44, 531.

[25] C. Neville, Biology of Fibrous Composites, Cambridge University Press, Cambridge 1993.

[26] Y. Bouligand, Tissue Cell 1972, 4, 189.

[27] Y. Bouligand, in Liquid crystalline order in polymers (Ed: A. Blumstein), Academic Press, New-York, USA 1978, 261.

[28] T. Engels, W. von Rybinski, J. of Mat. Chem. 1998, 8, 1313.

[29] R. Smith, D. R. Sabatino, T. J. Praisner, Exp. in Fluids 2001, 30, 190.

[30] H. Hirschmann, V. Reiffenrath, in Handbook of Liquid Crystals, Vol. 2A (Eds. D. Demus, J. Goodby, G. W. Gray, H.-W. Spiess, V. Vill), Wiley-VCH, Weinheim, Germany 1998, p. 199.

[31] N. Tamaoki, Adv. Mat. 2001, 13, 1135. 
[32] S.-T. Wu and D.-K. Yang, Reflective Liquid Crystal Displays, John Wiley \& Sons Ltd., Chichester, England 2001.

[33] S. P. Palto, L. M. Blinov, M. I. Barnik, V. V. Lazarev, B. A. Umanskii, N. M. Shtykov, Crystallogr. Rep. 2011, 56, 667.

[34] S. J. Woltman, G. D Jay and G. P. Crawford (Eds), Liquid Crystals, World Scientific, Singapore 2007.

[35] H. Kelker, R. Hatz. Handbook of Liquid Crystals, Verlag Chemie, Weinheim, Germany 1980, pp. 293-337.

[36] V. A. Belyakov, V. E. Dmitrienko, Sov. Sci. Rev. A Phys. 1989 13, 1.

[37] M. Mitov, Les cristaux liquides, Presses Universitaires de France, Paris, France 2000, pp. 4449.

[38] I. Dierking, Textures of Liquid Crystals, Wiley-VCH, Weinheim, Germany 2003, Chap. 5.

[39] M. A. Osipov, H.-G. Kuball, Eur. Phys. J. E 2001, 5, 589.

[40] K. Gansel, M. Thiel, M. S. Rill, M. Decker, K. Bade, V. Saile, G. von Freymann, S. Linden, M. Wegener, Science 2009, 325, 1513.

[41] M. Hird, K. J. Toyne, G. W. Gray, S. E. Day, D. G. Mc Donnell, Liq. Cryst. 1993, 15, 123.

[42] F. Hessel, H. Finkelmann, Polym. Bull. 1985, 14, 375.

[43] F. Hessel, H. Finkelmann, Makromol. Chem. 1988, 189, 2275.

[44] Q. F. Zhou, H.-M. Li, X. D. Feng, Macromol. 1987, 20, 233.

[45] N. Leroux, L.-C. Chien, Proc. ACS 96 1996, 37, 195.

[46] C. Mauguin, Bull. Soc. Fr. Minér. Cristallogr. 1911, 34, 3.

[47] P.-G. de Gennes, J. Prost, The Physics of Liquid Crystals, Oxford University Press, Oxford, UK 1993, pp. 268-269.

[48] M. Born, E. Wolf, Principle of Optics, Cambridge University Press, UK 1999. 
[49] L.-C. Chien, M.-F. Nabor, U. Müller, N. Leroux, D. K. Yang, J. W. Doane, M. N. Boyden, A. J. Walz, C. M. Citano, Proc. ACS 95 1995, 72, 492.

[50] N. Leroux, W. J. Fritz, J. W. Doane, L.-C. Chien, Mol. Cryst. Liq. Cryst. 1995, 261, 465.

[51] D. J. Dyer, U. P. Schröder, K.-P. Chan, R. J. Twieg, Chem. Mater. 1997, 9, 1665.

[52] J. Brink, N. G. van der Berg, L. C. Prinsloo, I. J. Hodgkinson, J. Phys. D: Appl. Phys. 2007, 40, 2189.

[53] N. Y. Ha, Y. Takanishi, K. Ishikawa, H. Takezoe, Optics Express 2007, 15, 1024.

[54] S. M. Jeong, Y. Ohtsuka, N. Y. Ha, Y. Takanishi, K. Ishikawa, H. Takezoe, S. Nishimura, G. Suzaki, Appl. Phys. Lett. 2007, 90, 211106.

[55] N. Y. Ha, Y. Ohtsuka, S. M. Jeong, S. Nishimura, G. Suzaki, Y. Takanishi, K. Ishikawa, H. Takezoe, Nature Mater. 2008, 7, 43.

[56] N. Y. Ha, S. M. Jeong, S. Nishimura, H. Takezoe, Adv. Mater. 2010, 22, 1617.

[57] J. Guo, J. Sun, K. Li, H. Cao, H. Yang, Liq. Cryst. 2008, 35, 87.

[58] M. Nascimento, F. M. Zanetti, M. L. Lyra, I. N. de Oliveira, Phys. Rev. E 2010, 81, 031713.

[59] R. R. da Silva, F. M. Zanetti, I. N. de Oliveira, Phys. Rev. E 2010, 82, 061704.

[60] J. Guo, H. Wu, F. Chen, L. Zhang, W. He, H. Yang, J. Wei, J. Mater. Chem. 2010, 20, 4094.

[61] N. Y. Ha, S. M. Jeong, S. Nishimura, H. Takezoe, Optics Express 2010, 18, 26339.

[62] J. Guo, F. Chen, Z. Qu, H. Yang, J. Wei, J. Phys. Chem. B 2011, 115, 861.

[63] T. J. White, S. A. Cazzell, A. S. Freer, D.-K. Yang, L. Sukhomlinova, L. Su, T. Kosa, B. Taheri, T. J. Bunning, Adv. Mater. 2011, 23, 1389.

[64] H. Choi, S. Nishimura, T. Toyooka, K. Ishikawa, H. Takezoe, Adv. Funct. Mat. 2011, 21, 3430.

[65] A. H. Gevorgyan, Phys. Rev. E 2012, 85, 021704.

[66] F. Vicentini, J. Cho, L.-C. Chien, Liq. Cryst. 1998, 24, 483.

[67] R. A. M. Hikmet, R. Polesso, Adv. Mater. 2002, 14, 502. 
[68] J. Xiao, D. Zhao, H. Cao, H. Yang, Liq. Cryst. 2007, 34, 473.

[69] Z. Bian, K. Li, W. Huang, H. Cao, H. Yang, Appl. Phys. Lett. 2007, 91, 201908.

[70] U. A. Hrozhyk, S. V. Serak, N. V. Tabiryan, T. J. Bunning, Adv. Mater. 2007, 19, 3244.

[71] M. Lee, H. Jang, S.-W. Choi, K. Song, Bull. Korean. Chem. Soc. 2009, 30, 1625.

[72] G. Petriashvili, M. A. Matranga, M. P. De Santo, G. Chilaya, R. Barberi, Optics Express 2009, $17,4553$.

[73] C.-K. Chang, H.-L. Kuo, M.-C. Peng, Optics Lett. 2010, 35, 2439.

[74] S.-C. Jeng, S.-J. Hwang, Y.-H. Hung, S.-C. Chen, Optics Express 2010, 18, 22572.

[75] R. A. M. Hikmet, H. Kemperman, Nature 1998, 392, 476.

[76] R. A. M. Hikmet, H. Kemperman, Liq. Cryst. 1999, 26, 1645.

[77] A. Castellanos-Moreno, P. Castro-Garay, S. Gutiérrez-López, R. A. Rosas-Burgos, A. CorellaMadueño, J. Adrian Reyes, J. Appl. Phys. 2009, 106, 023102.

[78] S. S. Choi, S. M. Morris, W. T. S. Huck, H. J. Coles, Adv. Mater. 2010, 22, 53.

[79] M. Mathews, R. S. Zola, D.-K. Yang, Q. Li, J. Mater. Chem. 2011, 21, 2098.

[80] V. T. Tondiglia, L. V. Natarajan, C. A. Bailey, M. M. Duning, R. L. Sutherland, D. Ke-Yang, A. Voevodin, T. J. White, T. J. Bunning, J. Appl. Phys. 2011, 110, 053109.

[81] V. Shibaev, A. Bobrovsky, N. Boiko, Prog. Polym. Sci. 2003, 28, 729.

[82] T. J. White, R. L. Bricker, L. V. Natarajan, S. V. Serak, N. V. Tabiryan, T. J. Bunning, Soft Matter 2009, 5, 3623.

[83] M. Mathews, R. S. Zola, S. Hurley, D.-K. Yang, T. J. White, T. J. Bunning, Q. Li, J. Am. Chem. Soc. 2010, 132, 18361.

[84] T. J. White, A. S. Freer, N. V. Tabiryan, T. J. Bunning, J. Appl. Phys. 2010, 107, 073110.

[85] M. Rivera, J. A. Reyes, Appl. Phys. Lett. 2007, 90, 023513. 
[86] H. Yang, K. Mishima, K. Matsuyama, K.-I. Hayashi, H. Kikuchi, T. Kajiyama, Appl. Phys. Lett. 2003, 82, 2407.

[87] X. Yuan, L. Zhang, H. Yang, Liq. Cryst. 2010, 37, 445.

[88] V. E. Dmitrienko, V. A. Belyakov, Sov. Phys. Solid State 1974, 15, 2213.

[89] H. Takezoe, Y. Ouchi, A. Sugita, M. Hara, A. Fukuda, E. Kuze, Jap. J. of Appl. Phys. 1982, 21, L390.

[90] A. Sugita, H. Takezoe, Y. Ouchi, A. Fukuda, E. Kuze, N. Goto, Jap. J. of Appl. Phys. 1982, 21, 1543.

[91] H. Takezoe, K. Hashimoto, Y. Ouchi, M. Hara, A. Fukuda, E. Kuze, Mol. Cryst. Liq. Cryst. $1983,101,329$.

[92] H. Takezoe, Y. Ouchi, M. Hara, A. Fukuda, E. Kuze, Jap. J. of Appl. Phys. 1983, 22, 1080.

[93] E. Miraldi, C. Oldano, P. Taverna, L. Trossi, Mol. Cryst. Liq. Cryst. 1983, 1, 155.

[94] I. Abdulhalim, L. Benguigui, R. Weil, J. Phys. (France) 1985, 46, 815.

[95] A. Lakhtakia, W. S. Weiglhofer, Microw. Opt. Technol. Lett. 2002, 35, 397.

[96] J. A. Polo, A. Lakhtakia, Microw. Opt. Technol. Lett. 2002, 35, 397.

[97] F. Wang, A. Lakhtakia, Opt. Commun. 2004, 235, 133.

[98] M. Z. Arutyunyan, A. A. Gevorgyan, G. A. Vardanyan, J. Opt. Technol. 2007, 74, 236.

[99] A. Lakhtakia, Phys. Lett. A 2010, 374, 3887.

[100] A. Michelson, Phil. Mag. 1911, 21, 554.

[101] S. A. Jewell, P. Vukusic, N. W. Roberts, New J. of Phys. 2007, 9, 1.

[102] D. M. Makow, C. Leroy-Sanders, Nature 1978, 276, 48.

[103] R. Maurer, D. Andrejewski, F.-H. Kreuzer, A. Miller, SID 90 Digest 1990, 110.

[104] W. Schlichting, S. Faris, B. Fan, J. Haag, Z. Lu, S. Kane, L. Li, T. Milster, H. Luo, Jap. J. of Appl. Phys. 1997, 36, 587. 
[105] P. Sixou, J. Nourry, H. Guillard, C. Gautier, Mol. Cryst. Liq. Cryst. 2001, 365, 467.

[106] C. Bohley, T. Scharf, Optics Comm. 2002, 214, 193.

[107] J. Hwang, M. H. Song, B. Park, S. Nishimura, T. Toyooka, J. W. Wu, Y. Takanishi, K. Ishikawa, H. Takezoe, Nature Mater. 2005, 4, 383.

[108] R. Ozaki, T. Sanda, H. Yoshida, Y. Matsuhita, M. Ozaki, K. Yoshino, Jap. J. of Appl. Phys. 2006, 45, 493.

[109] Y. Huang, Y. Zhou, S.-T. Wu, Optics Express 2007, 25, 6414.

[110] H. Choi, J. Kim, S. Nishimura, T. Toyooka, F. Araoka, K. Ishikawa, J. W. Wu, H. Takezoe, Adv. Mater. 2010, 22, 2680.

[111] Y. Bouligand, J. Phys. 1969, 30, C4.

[112] F. Duspiva, M. Cerny, Z. Vergl. Physiol. 1934, 21, 267.

[113] F. Rucker, Z. Vergl. Physiol. 1934, 21, 275.

[114] G. Richards, The integument of arthropods, thesis, Univ. Minnesota, USA 1951.

[115] A. C. Neville, J. Insect. Physiol. 1977, 23, 1267.

[116] M. Mitov, A. Boudet, P. Sopena, Eur. Phys. J. B 1999, 8, 327.

[117] C. Binet, M. Mitov, A. Boudet, Mol. Cryst. Liq. Cryst. 2000, 339, 111.

[118] A. Boudet, C. Binet, M. Mitov, C. Bourgerette, E. Boucher, Eur. Phys. J. E 2000, 2, 247.

[119] M. Mitov, C. Binet, A. Boudet, C. Bourgerette, Mol. Cryst. Liq. Cryst. 2001, 358, 209.

[120] M. Mitov, C. Binet, C. Bourgerette, in Liquid Crystals V, Vol. 4463 (Ed. I.-C. Khoo), SPIE, Washington, USA 2001, 11.

[121] D. C. Zografopoulos, E. E. Kriezis, M. Mitov, C. Binet, Phys. Rev. E 2006, 73, 061701.

[122] M. Belalia, M. Mitov, C. Bourgerette, A. Krallafa, M. Belhakem and D. Bormann, Phys. Rev. E 2006, 74, 051704. 
[123] T. J. Bunning, D. L. Vezie, P. F. Lloyd, P. D. Haaland, E. L. Thomas, W. W. Adams, Liq. Cryst. 1994, 16, 769.

[124] J. Pierron, A. Boudet, P. Sopena, M. Mitov, P. Sixou, Liq. Cryst. 1995, 19, 257.

[125] J. Pierron, V. Tournier-Lasserve, P. Sopéna, A. Boudet, P. Sixou, M. Mitov, J. Phys. II France 1995, 5,1635 .

[126] A. Boudet, C. Binet, M. Mitov, C. Bourgerette, E. Boucher, Eur. Phys. J. E 2000, 2, 247.

[127] A. Boudet, M. Mitov, C. Bourgerette, T. Ondarçuhu, R. Coratger, Ultramicroscopy 2001, 88, 219.

[128] S. Furumi, N. Tamaoki, Adv. Mater. 2010, 22, 886.

[129] Y. J. Kwon, W. J. Lee, S. H. Paek, Mol. Cryst. Liq. Cryst. 2002, 377, 325.

[130] J. Xiao, H. Cao, W. He, Z. Ma, J. Geng, L. Wang, G. Wang, H. Yang, J. of Appl. Polym. Sci. 2007, 105, 2973.

[131] P. Sixou, C. Gautier, H. Guillard, Mol. Cryst. Liq. Cryst. 2001, 364, 665.

[132] J. Guo, F. Liu, L. Zhang, H. Cao, H. Yang, Polym. Eng. and Sci. 2009, 937.

[133] X. Cui, Q. Huang, T. Liu, H. Cao, Q. Liu, Z. Yang, H. Yang, J. Appl. Phys. 2010, 107, 063711.

[134] C. Binet, M. Mitov and M. Mauzac, J. Appl. Phys. 2001, 90, 1730.

[135] I. Dierking, Adv. Mat. 2000, 12, 167.

[136] I. Dierking, Polym. Chem. 2010, 1, 1153.

[137] S. Sonin, N. A. Churochkina, Polym. Sci., Ser. A 2010, 52, 463.

[138] D.-K. Yang, L.-C. Chien, Y. K. Fung, in Liquid Crystals in Complex Geometries, Eds: G. P. Crawford, S. Zumer, Talor \& Francis, London, UK 1996, Ch. 5.

[139] H. Yuan, in Liquid Crystals in Complex Geometries, Eds: G. P. Crawford, S. Zumer, Talor \& Francis, London, UK 1996, Ch. 12.

[140] D. J. Broer, J. Lub, G. N. Mol, Nature 1995, 378, 467. 
[141] D. J. Broer, J. Lub, G. N. Mol, Macromol. Symp. 1997, 117, 33.

[142] D. J. Broer, G. N. Mol, J. A. M. M. van Haaren, J. Lub, Adv. Mat. 1999, 11, 573.

[143] J. Lub, D. J. Broer, P. van de Witte, Prog. Org. Coat. 2002, 45, 211.

[144] D. J. Broer, Curr. Opin. Solid. St. M. 2002, 6, 553.

[145] J. Lub, D. J. Broer, R. T. Wegh, E. Peeters, B. M. I. van der Zande, Mol. Cryst. Liq. Cryst. $\mathbf{2 0 0 5}, 429,77$.

[146] R. A. M. Hikmet, in Chromogenic Phenomena in Polymers, Vol. 888 (Eds; A. A. Jenekhe, D. J. Kiserow), ACS Symposium Series, Orlando, USA 2005, Ch. 21.

[147] L. Zhang, W. He, X. Yuan, W. Hu, H. Cao, H. Yang, S. Zhu, Liq. Cryst. 2010, 37, 1275.

[148] F. Li, L. Wang, W. Sun, H. Liu, X. Liu, Y. Liu, H. Yang, Polym. Adv. Technol. 2012, 23, 143.

[149] D. Coates, M. J. Goulding, S. Greenfield, J. M. W. Hanmer, S. A. Marden, O. L. Parri, Proc. of SID 96 1996, 67.

[150] D. Coates, M. J. Goulding, S. Greenfield, J. M. W. Hanmer, S. A. Marden, O. L. Parri, M. Verrall, J. Ward, Proc. of IDW 96 1996, 309.

[151] J. C. Kralik, B. Fan, H. Vithana, L. Li, S. M. Faris, Mol. Cryst. Liq. Cryst. 1997, 301, 249.

[152] D. Coates, O. Parri, M. Verrall, K. Slaney, S. Marden, Macromol. Symp. 2000, 154, 59.

[153] K.-S. Bae, U. Cha, Y.-J. Lee, Y.-K. Moon, H.-C. Choi, J.-H. Kim, C.-J. Yu, Optics Express 2011, 19, 8291 .

[154] D. Katsis, D.U. Kim, H.P. Chen, L.J. Rothberg, S. H. Chen, Chem. Mater. 2001, 13, 643.

[155] J.-F. Li, S. M. Faris, SID 96 Digest 1996, 28, 111.

[156] J.-F. Li, B. Fan, L. Li, SID 99 Digest 1999, 30, 1066.

[157] H. Guillard, P. Sixou, Liq. Cryst. 2001, 28, 933.

[158] H. Guillard, P. Sixou, L. Reboul, A. Perichaud, Polymer 2001, 42, 9753.

[159] P. Sixou, C. Gautier, Polym. Adv. Technol. 2002, 13, 329. 
[160] P. Sixou, C. Gautier, Liq. Cryst. 2002, 29, 467.

[161] R. Bartolino, N. Scaramuzza, D. E. Lucchetta, E. S. Barna, A. Th. Ionescu, L. M. Blinov, J. Appl. Phys. 1999, 85, 2870.

[162] D. Sikharulidze, A. Tchanishvili, G. Petriashvili, N. Scaramuzza, R. Barberi, R. Bartolino, Appl. Phys. Lett. 1999, 75, 1013.

[163] S. Relaix, C. Bourgerette, M. Mitov, Appl. Phys. Lett. 2006, 89, 251907.

[164] S. Relaix, C. Bourgerette, M. Mitov, Liq. Cryst. 2007, 34, 1009.

[165] B. Fan, S. Vartak, J. N. Eakin, S. M. Faris, Appl. Phys. Lett. 2008, 92, 061101.

[166] B. Fan, S. Vartak, J. N. Eakin, S. M. Faris, J. Appl. Phys. 2008, 104, 023108.

[167] L. Zhang, K. Li, W. Hu, H. Cao, Z. Cheng, W. He, J. Xiao, H. Yang, Liq. Cryst. 2011, 38, 673.

[168] L. V. Natarajan, J. R. Voss, V. P. Tondiglia, D.-K. Yang, T. J. White, T. J. Bunning, in Liquid Crystals XIV, Vol. 7775 (Ed. I.-C. Khoo), SPIE, Washington, USA 2010, 1.

[169] A. Lavernhe, M. Mitov, C. Binet, C. Bourgerette, Liq. Cryst. 2001, $28,803$.

[170] R. Guo, K. Li, H. Cao, X. Wu, G. Wang, Z. Cheng, F. Wang, H. Zhang, H. Yang, Polymer 2010, 51, 5990 .

[171] X. Wu, L. Yu, H. Cao, R. Guo, K. Li, Z. Cheng, F. Wang, Z. Yang, H. Yang, Polymer 2011, 52, 5636.

[172] M. Mitov, E. Nouvet, N. Dessaud, Eur. Phys. J. E 2004, 15, 413.

[173] E. Nouvet, M. Mitov, Mol. Cryst. Liq. Cryst. 2004, 413, 515.

[174] J. Guo, J. Sun, L. Zhang, K. Li, H. Cao, H. Yang, S. Zhu, Polym. Adv. Technol. 2008, 19, 1504.

[175] R. W. Guo, H. Cao, C. Y. Yang, X. J. Wu, Q. Y. Meng, T. Liu, W. L. He, Z. H. Cheng, H. Yang, Liq. Cryst. 2010, 37, 311.

[176] S. H. Chen, J. C. Mastrangelo, R. J. Jin, Adv. Mat. 1999, 11, 1183. 
[177] S. H. Chen, R. J. Jin, D. Katsis, J. C. Mastrangelo, S. Papernov, A. W. Schmid, Liq. Cryst. 2000, 27, 201.

[178] P. van de Witte, M. Brehmer, J. Lub, J. Mater. Chem. 1999, 9, 2087.

[179] K. Robbie, M. J. Brett, J. Vac. Sci., Technol. 1997, A15, 1460.

[180] N. O. Young, J. Kowal, Nature 1959, 183, 104.

[181] K. Robbie, D. J. Broer, M. J. Brett, Nature 1999, 399, 764.

[182] J. C. Sit, D. J. Broer, M. J. Brett, Liq. Cryst. 2000, 27, 387.

[183] S. Mazkedian, S. Melone, F. Rustichelli, J. Phys. 1976, 37, 731.

[184] E. Hadjo, A. Cemal Eringen, J. Opt. Soc. Am. 1979, 69, 1017.

[185] Z. Lu, L. Li, H. Vithana, Y. Jiang, S. M. Faris, Mol. Cryst. Liq. Cryst. 1997, 301, 237.

[186] S. Giridhar, K. A. Suresh, G. S. Ranganath, J. Opt. Soc. Am. A 2002, 19, 19.

[187] S. Kutter, M. Warner, Eur. Phys. J. E 2003, 12, 515.

[188] Q. Hong, T. X. Wu, S.-T. Wu, Liq. Cryst. 2003, 30, 367.

[189] J.-Y. Chen, L.-W. Chen, J. Phys. D: Appl. Phys. 2005, 38, 1118.

[190] S. Caveney, Proc. Roy. Soc. Lond. B 1971, 178, 205.

[191] I. Hodgkinson, S. Lowrey, L. Bourke, A. Parker, M. W. McCall, Applied Optics 2010, 49, 4558.

[192] M. Makow, Appl. Optics 1980, 19, 1274.

[193] H. Song, B. Park, K.-C. Shin, T. Ohta, Y. Tsunoda, H. Hoshi, Y. Takanishi, K. Ishikawa, J. Watanabe, S. Nishimura, T. Toyooka, Z. Zhu, T. M. Swager, H. Takezoe, Adv. Mat. 2004, 16, 779.

[194] H. Song, K.-C. Shin, B. Park, Y. Takanishi, K. Ishikawa, J. Watanabe, S. Nishimura, T. Toyooka, Z. Zhu, T. M. Swager, H. Takezoe, Sci. and Technol. of Adv. Mat. 2004, 5, 437.

[195] A. A. Gevorgyan, K. V. Papoyan, O. V. Pikichyan, Optics and Spectro. 2000, 88, 586. 
[196] M. H. Song, N. Y. Ha, K. Amemiya, B. Park, Y. Takanishi, K. Ishikawa, J. W. Wu, S. Nishimura, T. Toyooka, H. Takezoe, Adv. Mater. 2006, 18, 193.

[197] Y. Ha, S. M. Jeong, S. Nishimura, H. Takezoe, Appl. Phys. Lett. 2010, 96, 15330.

[198] M. Mitov, N. Dessaud, Nature Mater. 2006, 5, 361.

[199] M. Mitov, N. Dessaud, Liq. Cryst. 2007, 34, 183.

[200] M. Mitov, N. Dessaud, C. R. Acad. Sci. Chimie 2008, 11, 253.

[201] S. Relaix, M. Mitov, J. Appl. Phys. 2008, 104, 033539.

[202] G. Agez, M. Mitov, J. Phys. Chem. B 2011, 115, 6421.

[203] A. J. Slaney, I. Nishiyama, P. Styring, J. W. Goodby, J. Mater. Chem. 1992, 2, 805.

[204] P. Styring, J. D. Vuijk, A. J. Slaney, J. W. Goodby, J. Mater. Chem. 1993, 3, 399.

[205] H. Stegemeyer, K. Siemensmeyer, W. Sucrow, L. Appel, Z. Naturforsch. A 1989, 44a, 1127.

[206] I. Dierking, F. Giesselmann, P. Zugenmaier, W. Kuczynski, S. T. Lagerwall, B. Stebler, Liq. Cryst. 1993, 13, 45.

[207] H.-G. Kuball, T. Muller, H.-G. Weyland, Mol. Cryst. Liq. Cryst. 1992, 215, 271.

[208] H.-G. Kuball, T. Muller, H. Bruning, A. Schonhofer, Mol. Cryst. Liq. Cryst. 1995, 261, 845.

[209] I. Dierking, F. Giesselmann, P. Zugenmaier, K. Mohr, H. Zaschke, W. Kuczynski, Z. Naturforsch 1994, 49a, 1081.

[210] I. Dierking, F. Giesselmann, P. Zugenmaier, K. Mohr, H. Zaschke, W. Kuczynski,, Liq. Cryst. 1995, $18,443$.

[211] S. Relaix, M. Mitov, Liq. Cryst. 2008, 35, 1037.

[212] J. Guo, H. Cao, J. Wei, D. Zhang, F. Liu, G. Pan, D. Zhao, W. He, H. Yang, Appl. Phys. Lett. 2008, 93, 201901.

[213] J. Guo, H. Yang, R. Li, N. Ji, X. Dong, H. Wu, J. Wei, J. Phys. Chem. C 2009, 113, 16538.

[214] J. Guo, F. Liu, F. Chen, J. Wei, H. Yang, Liq. Cryst. 2010, 37, 171. 
[215] M. E. McConney, V. P. Tondiglia, J. M. Hurtubise, T. J. White, T. J. Bunning, Chem. Comm. 2011, 47, 505 .

[216] M. E. McConney, V. P. Tondiglia, J. M. Hurtubise, L. V. Natarajan, T. J. White, T. J. Bunning, Adv. Mater. 2011, 23, 1453.

[217] Z. Y. Yang, M. Zhao, P. X. Lu, Y. F. Lu, Optics Letters 2010, 35, 2588.

[218] Z. Y. Yang, M. Zhao, Y. F. Lu, J. Light. Technol. 2010, 28, 3055.

[219] H. Sarkissian, B. Ya. Zeldovich, N. V. Tabiryan, Optics Letters 2006, 31, 1678.

[220] P. Castro-Garay, J. A. Reyes, R. Ramos-Garcia, Appl. Phys. Lett. 2007, 91, 113519.

[221] P. Castro-Garay, J. A. Reyes, R. Ramos-Garcia, Mol. Cryst. Liq. Cryst. 2008, 488, 31.

[222] P. Castro-Garay, J. A. Reyes, R. Ramos-Garcia, Mol. Cryst. Liq. Cryst. 2008, 495, 586.

[223] P. Castro-Garay, J. A. Reyes, A. Corella-Madueño, Appl. Phys. Lett. 2009, 94, 163504.

[224] C. Tasolamprou, M. Mitov, D. C. Zografopoulos, E. E. Kriezis, Optics Comm. 2009, 282, 903.

[225] M. Mitov, Sensitive Matter-Foams, Gels, Liquid Crystals, and Other Miracles, Harvard University Press, Cambridge, USA 2012.

[226] Hl. de Vries, Acta. Cryst. 1951, 4, 219.

[227] The subsidiary maxima are sometimes called Pendellösung fringes by analogy with the case of X-ray or neutron diffraction by perfect crystals. The phenomenon of Pendellösung consists of the beating inside a crystal of two coherent wave fields originated by double refraction in the case of Bragg reflection. By knowing the thickness of the cholesteric layer, it is possible to deduce the value of the average refractive index $n$ from the separation $\delta \lambda$ between two adjacent minima of order $n$ and $(n+1)$, when observed experimentally. Reciprocally, the layer thickness may be deduced from interference patterns when $n$ is known. See Ref. [228] for more details. Alternatively, the cell gap may be deduced by using the interferometric method 
in an empty cell. ${ }^{[229]}$ The oscillations in the reflection or transmission spectrum are the direct result of the Fabry-Perot effect.

[228] S. Mazkedian, S. Melone, F. Rustichelli, Phys. Rev. A 1976, 14, 1190.

[229] K. H. Yang, J. Appl. Phys. 1988, 64, 4780.

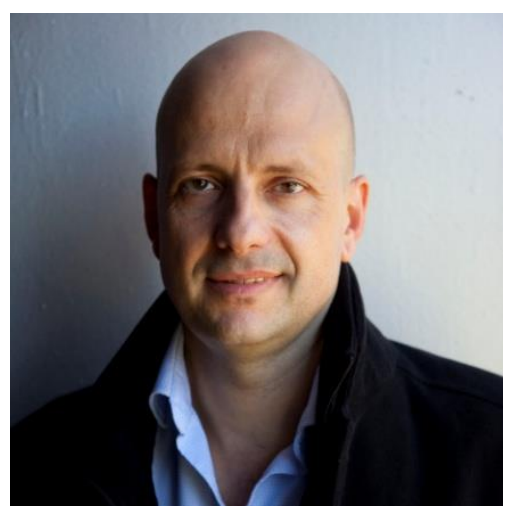

Michel Mitov studied physics at the University of Nice-Sophia Antipolis (France), where he obtained his Ph.D thesis supervised by Dr. P. Sixou. As a postdoctoral fellow he joined the group of Prof. S. T. Lagerwall at Chalmers University of Technology (Sweden). He is Director of Research at CNRS (National Center for Scientific Research, France) and leader of Liquid Crystal Group at Centre d'Elaboration de Matériaux et d’Etudes Structurales (CEMES) in Toulouse. His current research interests are the optical and structural properties of cholesteric-liquid-crystalline materials and their use for the self-organization of nanoparticles. He is the author of monographs on liquid crystals (Les Cristaux Liquides, Presses Universitaires de France, 2000) and soft matter (Sensitive Matter-Foams, gels, liquid crystals and other miracles, Harvard University Press, USA, 2012). 